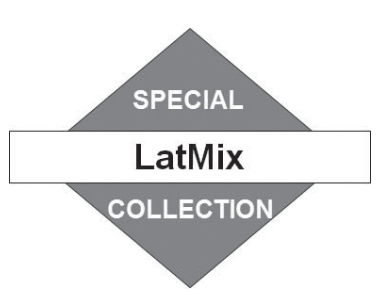

\title{
THE LATMIX SUMMER CAMPAIGN Submesoscale Stirring in the Upper Ocean
}

by Andrey Y. Shcherbina, Miles A. Sundermeyer, Eric Kunze, Eric D’Asaro, Gualtiero Badin,

Daniel Birch, Anne-Marie E. G. Brunner-Suzuki, Jörn Callies, Brandy T. Kuebel Cervantes, Mariona Claret, Brian Concannon, Jeffrey Early, Raffaele Ferrari, Louis Goodman,

Ramsey R. Harcourt, Jody M. Klymak, Craig M. Lee, M.-Pascale Lelong, Murray D. Levine, Ren-Chieh lien, Amala Mahadevan, James C. McWilliams, M. Jeroen Molemaker, Sonaljit Mukherjee, Jonathan D. Nash, Tamay Özgökmen, Stephen D. Pierce, Sanjiv Ramachandran, Roger M. Samelson,

Thomas B. Sanford, R. Kipp Shearman, Eric D. Skyllingstad, K. Shafer Smith, Amit Tandon, John R. Taylor, Eugene A. Terray, Leif N. Thomas, and James R. Ledwell

\section{LatMix combines shipboard, autonomous, and airborne field observations with modeling to improve understanding of ocean stirring across multiple scales.}

D ispersion of natural and anthropogenic tracers in the ocean is traditionally conceptualized as a two-stage process: The first step, stirring, is an adiabatic rearrangement of water parcels that does not change their potential temperature, salinity, or other tracer concentrations; it tends to stretch tracer patches into convoluted streaks and therefore enhances overall variance of tracer gradients. Molecular diffusion then acts to reduce small-scale gradients and effects the ultimate mixing (Eckart 1948; Garrett 2006). In practice, all small-scale processes not resolved in a particular numerical or
AFFiliations: ShCHERbina, D'AsARo, HaRCourt, LeE, Lien, AND SANFORD-University of Washington, Seattle, Washington; Sundermeyer, BiRch, Brunner-Suzuki, Goodman, Mukherjee, RAMACHANDRAN, AND TANDON-University of Massachusetts Dartmouth, North Dartmouth, Massachusetts; KunZE-Seattle, Washington; BADIN-University of Hamburg, Hamburg, Germany; CALLIES-Massachusetts Institute of Technology/Woods Hole Oceanographic Institution Joint Program in Oceanography, Cambridge, Massachusetts; Kuebel Cervantes, Levine, Nash, Pierce, Samelson, Shearman, and Skyllingstad-Oregon State University, Corvallis, Oregon; Claret, Mahadevan, Terray, and LEDWELL-Woods Hole Oceanographic Institution, Woods Hole, Massachusetts; ConCANnON-Naval Air Systems Command, Patuxent River, Maryland; EARLY AND LeLONG—NorthWest Research Associates, Redmond, Washington; FerRARI-Massachusetts Institute of Technology, Cambridge, Massachusetts; KLYMAK-University of Victoria, Victoria, British Columbia, Canada; McWILLIAMS AND
MolemaKer-University of California, Los Angeles, Los Angeles, California; ÖZgÖKMEN-University of Miami, Miami, Florida; SMITH—New York University, New York, New York; TAYLORUniversity of Cambridge, Cambridge, United Kingdom; TномаsStanford University, Stanford, California

CORRESPONDING AUTHOR: Andrey Shcherbina, Applied Physics Laboratory, University of Washington, 1013 NE 40th St., Seattle, WA 98105

E-mail: ashcherbina@apl.uw.edu

The abstract for this article can be found in this issue, following the table of contents. DOI:10.II75/BAMS-D-I4-000I5.I

A supplement to this article is available online (I0.II75/BAMS-D-14-000I5.2)

In final form 24 October 2014 (C)2015 American Meteorological Society 
analytic framework (e.g., Reynolds-averaged NavierStokes equations) are often lumped into mixing with the understanding that it may include unresolved stirring as well. Within the strongly stratified ocean interior, a clear distinction can be made between isopycnal processes, which act along surfaces of constant potential density (or, more strictly, neutral surfaces; Montgomery 1940; McDougall 1984), and diapycnal processes, which act across these surfaces (Gregg 1987; MacKinnon et al. 2013).

Interpretation of lateral dispersion of tracers in the ocean in terms of mixing is fraught with ambiguity. The unresolved flux $\mathbf{J}_{T}$ of a tracer $T$ ascribed to lateral mixing is commonly parameterized with Fickian diffusion law,

$$
J_{T}=-K_{h} \nabla T,
$$

where $K_{h}$ is the effective diffusivity and $\nabla T$ is the resolved tracer gradient. However, it has been long recognized that $K_{h}$ depends strongly on the spatial and temporal scales being considered (Stommel 1949; Ozmidov 1958). Therefore, any estimate of $K_{h}$ must be accompanied with the specification of scales, which are themselves somewhat arbitrarily defined (Okubo 1976). These ambiguities can be overcome by understanding and modeling the processes responsible for lateral stirring of tracers.

Stirring cascades variance from large scales, where it is produced, to $O(1) \mathrm{cm}$ scales, where it is removed by molecular diffusion (Stern 1975). On the mesoscale $O(10-100) \mathrm{km}$, isopycnal stirring by geostrophic eddies is well understood (e.g., Smith and Ferrari 2009). Likewise, stirring by microscale $(0.01-1 \mathrm{~m})$ isotropic turbulence to the molecular scale has been studied for many decades and its physics is well established. In contrast, the dynamics that control stirring on the submesoscale $(0.1-10 \mathrm{~km})$, and the relative importance of various processes is not as well known. Contributions from both geostrophically balanced motions and internal gravity waves are expected, but their relative importance and the mechanisms by which they stir have not been quantified. Here, we discuss a recent campaign to improve our understanding of submesoscale stirring and mixing in the ocean interior.

Traditionally, dynamic signals at the submesoscale have been thought to be dominated by the ubiquitous presence of energetic broadband internal gravity waves (IGW). Decades of observations of these motions have clearly established their role in controlling diapycnal mixing (Gregg 1989; Polzin et al. 1995; MacKinnon et al. 2013). Although these motions have traditionally been modeled and conceptualized as a superposition of nearly linear IGW, significant deviations from this paradigm have been persistently observed, promoting speculations about the presence of coexisting vortical modes dominated by isopycnal velocities (Lien and Müller 1992; Sundermeyer et al. 2005; Pinkel 2014). IGW have long been thought to also have an important role in isopycnal mixing through shear dispersion, in which vertical internal-wave shear couples with diapycnal mixing (Young et al. 1982, hereafter YRG82). Traditional YRG82 scaling for the resulting effective isopycnal diffusivity is $K_{h} \sim\left\langle K_{v}\right\rangle\left\langle(\partial V / \partial z)^{2}\right\rangle f^{-2}$, where $\left\langle K_{v}\right\rangle$ is the average diapycnal diffusivity and $\left\langle(\partial V / \partial z)^{2}\right\rangle$ is the average variance of vertical shear dominated by finescale near-inertial waves. Dye-release studies have consistently found isopycnal diffusivities $O(1) \mathrm{m}^{2} \mathrm{~s}^{-1}$ at $1-5-\mathrm{km}$ scales, an order of magnitude larger than could be inferred from YRG82 theory (Ledwell et al. 1998; Sundermeyer and Ledwell 2001). This discrepancy may be due to 1) covariance between internalwave strain and shear-driven turbulence (Kunze and Sundermeyer 2014, manuscript submitted to J. Phys. Oceanogr.), 2) internal-wave Stokes drifts (Bühler et al. 2013), 3) subinertial vortical modes generated by breaking internal waves (Brunner-Suzuki et al. 2014), or 4) submesoscale processes unrelated to internal waves (Mahadevan and Tandon 2006; Capet et al. 2008; Thomas et al. 2008; Molemaker et al. 2010).

Recent high-resolution numerical models and targeted observations reveal intricate patterns of three-dimensional submesoscale fronts and filaments emerging from mesoscale features (Capet et al. 2008). A number of dynamical processes have been proposed to explain this mesoscale-submesoscale transition, including spontaneous instability of deep mixed layers, ageostrophic instability, frontogenesis, and direct wind forcing at mesoscale fronts (Boccaletti et al. 2007; Thomas et al. 2008). Numerical simulations suggest that non-quasigeostrophic baroclinic mixed layer instabilities can penetrate into the thermocline, leading to lateral stirring of tracers below the mixed layer (Badin et al. 2011).

It appears that both internal-wave and subinertial submesoscale dynamics cascade tracer variance and turbulent kinetic energy from larger scales, where they are generated, to dissipate at small scales, but the relative importance of various pathways has not been resolved (McWilliams et al. 2001; Müller et al. 2005; Molemaker et al. 2010). Moreover, it is presently unclear which processes participating in the cascade control downscale flux of variance (Garrett 2006).

The "Scalable Lateral Mixing and Coherent Turbulence" (LatMix) initiative led by the Office of Naval Research tackled the problem of submesoscale oceanic stirring spanning mesoscale to microscale processes from observational, theoretical, and numerical perspectives. Here, we present an overview 
of the major 2011 LatMix campaign involving three regional-class research vessels with numerous shipboard, towed, and autonomous instrument platforms, as well as airborne and satellite remote sensing and supporting numerical simulations.

FIELD EXPERIMENT. Aims. The LatMix initiative set out to address the following primary hypotheses for what drives isopycnal stirring and mixing at the submesoscale (while recognizing that the answer may be all or none of these processes):

1) internal-wave shear dispersion in which diapycnal mixing interacts with the vertical shear of the waves;

2) stirring associated with finescale potential vorticity anomalies (vortical modes) caused by internal-wave breaking;

3) progressive straining of tracer fields to smaller scales by mesoscale processes adequately described by quasigeostrophic dynamics; and

4) high-Rossby-number subinertial motions on the submesocale that are not quasigeostrophic, such as frontogenesis and mixed layer instabilities.

Experimental testing of these hypotheses required observations of submesoscale lateral tracer dispersion at various levels of background mesoscale straining and atmospheric forcing. The LatMix initiative included two major field campaigns, along with several modeling studies, to address processes ranging in scale from 0.01 to $100 \mathrm{~km}$. Here, we describe the first field experiment of summer 2011, conducted in the Sargasso Sea in a region of low to moderate straining and shallow mixed layers. The second campaign in late winter and spring 2012 (to be described in forthcoming articles) was situated in the Gulf Stream front, a strongly straining flow with strong surface fluxes and deep mixed layers.

Logistics and participants. Three regional class vessels participated in the field campaign: research vessels (R/Vs) Cape Hatteras, Endeavor, and Oceanus. Each vessel carried a wide range of shipboard, towed, and autonomous deployable instrumentation (see Table 1 and appendix). Additionally, R/V Cape Hatteras conducted a series of fluorescein and rhodamine dye releases that were surveyed with all three vessels. Dye patches were also surveyed by airborne lidar on board a Navy Lockheed P3 Orion aircraft. Broad context was established by analysis of satellite remote sensing products and operational numerical models.

Timely collective decision-making and coordination among the science parties on three research vessels required near-real-time integration and sharing of information. Shore support provided automated downloading, subsetting, and packaging of satellite and operational model sea surface height and temperature datasets. These were consolidated with telemetered instrument data streams in a common shoreside database, which was routinely replicated on the research vessels for local use. Positions of the vessels and all the autonomous platforms were plotted in near-real time on situation-awareness displays on the ships' bridges to aid navigation and avoid collisions. Technical details about the instrumentation and data products used in this study are given in the appendix.

Oceanographic and meteorological context. The summer LatMix experiment was conducted from 1 to 20 June 2011 in the Sargasso Sea approximately $250 \mathrm{~km}$ southsoutheast of Cape Hatteras and southeast of the Gulf Stream. The area was selected based on water clarity and relative proximity to shore, to optimize conditions for optical remote sensing by the aircraft and for the relative weakness of the mesoscale eddy field required for low- and moderate-dispersion studies. Bathymetry is generally flat and featureless, with the typical water depth of 4-5 km. Upper-500-m ocean stratification was characteristic of the summertime interior subtropical gyre (Fig. 1). Strong surface heating resulted in a shallow $(10-20 \mathrm{~m})$ and warm $\left(25^{\circ}-28^{\circ} \mathrm{C}\right)$ mixed layer. The buoyancy frequency below the mixed layer (20-30 m) was on the order of $0.02 \mathrm{~s}^{-1}$.

Fair summertime weather prevailed during the experiment (Fig. 2). Average air temperatures of $24.3^{\circ} \mathrm{C}$ were about $1^{\circ} \mathrm{C}$ cooler than the sea surface. Winds were typically light $\left(<10 \mathrm{~m} \mathrm{~s}^{-1}\right)$. Two short storms on 12 and 18 June brought precipitation of 50 and $150 \mathrm{~mm}$, respectively; maximum wind speeds of $15 \mathrm{~m} \mathrm{~s}^{-1}$; and short-term cooling.

\section{EXPERIMENT PROGRESS AND MAIN} FINDINGS. The summer 2011 LatMix field experiment consisted of weak-straining ${ }^{1}[O(0.05 f)$; 2-10 June] and moderate-straining [O(0.1f); 11-19 June] case studies, where $f=7.7 \times 10^{-5} \mathrm{rad} \mathrm{s}^{-1}$ is the

\footnotetext{
${ }^{1}$ Characteristic magnitudes of mesoscale $[O(10) \mathrm{km}]$ strain rate tensors in each case study were determined from the maps of mean near-surface $(0-50 \mathrm{~m})$ velocity, objectively interpolated from shipboard ADCP observations during the reconnaissance surveys.
} 
Coriolis frequency at $32^{\circ} \mathrm{N}$. Sites for the studies were selected based on satellite imagery and coordinated reconnaissance surveys. Geographically, the sites of weak- and moderate-straining studies overlapped; increased straining during the second case study was due to eastward expansion of several warm-core mesoscale eddies.

Each case study started with a coordinated $100 \mathrm{~km}$ $\times 100 \mathrm{~km}$ mesoscale survey carried out by the three vessels, followed by $\sim 100-\mathrm{kg}$ rhodamine dye releases on an isopycnal surface in the seasonal pycnocline at depths around $30 \mathrm{~m}$ (see appendix for dye injection details). A Lagrangian float was deployed within the dye patch and tracked acoustically. Drogued drifters and profiling Electromagnetic Autonomous Profiling Explorer (EM-APEX) floats were deployed in an array surrounding the patch. Subsequently, the vessels commenced nested surveys of the area centered on the dye: a $30 \mathrm{~km} \times 30 \mathrm{~km}$ radiator pattern covered by $\mathrm{R} / \mathrm{V}$ Oceanus, a $15 \mathrm{~km} \times 15 \mathrm{~km}$ butterfly pattern by $\mathrm{R} / \mathrm{V}$ Endeavor, and an $\mathrm{O}(1) \mathrm{km}$ adaptive survey by R/V Cape Hatteras (Fig. 3). The surveys were supplemented by a group of four Slocum gliders and one SeaGlider. The surveys were guided in real time by the advection of the Lagrangian float and drogued drifters, as well as by the integral of the R/V Cape Hatteras $150-\mathrm{kHz}$ acoustic Doppler current profiler (ADCP) velocity in the depth bin occupied by the dye. Details about

TABLE I. LatMix summer field campaign observational and modeling efforts along with the names and affiliations of the principal investigators or chief scientists. Woods Hole Oceanographic Institution (WHOI), School for Marine Science and Technology (SMAST), University of Massachusetts Dartmouth (UMassD), Oregon State University (OSU), Applied Physics Laboratory, University of Washington (APL-UW), NorthWest Research Associates (NWRA), University of Victoria (UVic), Naval Air Systems Command (NAVAIR), Massachusetts Institute of Technology (MIT), New York University (NYU), University of California, Los Angeles (UCLA), and Rosenstiel School of Marine and Atmospheric Science (RSMAS).

\begin{tabular}{|c|c|}
\hline R/V Cape Hatteras & J. Ledwell WHOI) \\
\hline Dye injection & J. Ledwell (WHOI) \\
\hline Acrobat CTD/fluorometer & M. Sundermeyer (SMAST UMassD) \\
\hline OSU Moving Vessel Profiler & M. Levine (OSU) \\
\hline Lagrangian float & E. D’Asaro (APL-UW) \\
\hline Drogued drifters & M. Sundermeyer (SMAST UMassD) \\
\hline SVP (global) drifters & M.-P. Lelong (NWRA) \\
\hline R/V Endeavor & J. Klymak (UVic) \\
\hline UVic Moving Vessel Profiler & J. Klymak (UVic) \\
\hline Gliders & R. Shearman (OSU) \\
\hline EM-APEX Profiling Floats & T. Sanford (APL-UW) \\
\hline R/V Oceanus & C. Lee (APL-UW) \\
\hline Triaxus Towed System & C. Lee (APL-UW) \\
\hline T-REMUS AUV & L. Goodman (SMAST UMassD) \\
\hline Thermistor chain & L. Goodman (SMAST UMassD) \\
\hline Hammerhead towyo & E. Kunze (APL-UW) \\
\hline Airborne lidar & B. Concannon (NAVAIR) \\
\hline \multicolumn{2}{|l|}{ Shore support and modeling: } \\
\hline $\begin{array}{l}\text { Remote sensing, data exchange, } \\
\text { and communications }\end{array}$ & R. Harcourt (APL-UW) \\
\hline Mesoscale QG modeling & R. Ferrari (MIT), S. Smith (NYU) \\
\hline Submesoscale modeling & J. McWilliams (UCLA), M. J. Molemaker (UCLA) \\
\hline Dispersion studies & T. Özgökmen (RSMAS) \\
\hline Subgrid process modeling & A. Tandon (UMassD), A. Mahadevan (WHOI) \\
\hline Large eddy simulations & M.-P. Lelong (NWRA) \\
\hline
\end{tabular}


the instrumentation and sampling are given in the appendix.

A series of eight smaller $(\sim 10-27 \mathrm{~kg})$ fluorescein dye releases were also performed in close proximity in depth and location to the rhodamine experiments. These releases were tracked by towed instruments for about a day each during continued surveys of the rhodamine patches. Four of these fluorescein dye patches were also surveyed for the first $6 \mathrm{~h}$ or so of their evolution by airborne lidar. During the daylight hours, after most of the fluorescein deployments, a microprobe-equipped autonomous underwater vehicle Turbulence Remote Environmental Measuring Unit (T-REMUS) was deployed to conduct $1-\mathrm{km}$ box surveys around a drogued Gateway buoy (see appendix) while Hammerhead was towyoed in $2-\mathrm{km}$ radius circles around it. Nested within surveys by Triaxus and Moving Vessel Profiler (MVP) instrument systems, these measurements collectively spanned horizontal scales of $0.03-30 \mathrm{~km}$ (Fig. 3).

A Google Earth interactive map of shipboard, autonomous, and airborne surveys during the summer 2011 LatMix experiment is available online as supplemental material (http://dx.doi.org//0.1/75 /BAMS-D-I4-000I5.2); see sidebar on supplemental material.

Weak-straining study. The weak-straining study started on 2 June 2011 at a quiescent site with lateral velocity gradients of $O(0.05 f)$ estimated at $10-\mathrm{km}$ scale using the mesoscale map of mean near-surface $(0-50 \mathrm{~m})$ ADCP velocities (Fig. 4) and simultaneously inferred from the drifter and dye convergence/elongation at kilometer scale. Lateral thermohaline variability was weak, with the exception of a $0.02 \mathrm{~km}^{-1}$ salinity gradient in the mixed layer and a few coherent features with $O(0.1)$ salinity anomalies in the pycnocline (Fig. 5). The upper-ocean flow was dominated by $6-9 \mathrm{~cm} \mathrm{~s}^{-1}$ inertial oscillations, as evident from the looping trajectories of the tracking drifters (Fig. 6). Subinertial advection was initially negligible but increased to $15 \mathrm{~cm} \mathrm{~s}^{-1}$ southward flow by 10 June.

A 1.5-km-long zonal streak of rhodamine dye was released on 4 June 2011 in the upper seasonal pycnocline with the vertical potential density gradient $-0.025 \mathrm{~kg} \mathrm{~m}^{-4}$ at potential density of $25.42 \mathrm{~kg} \mathrm{~m}^{-3}$ [root-mean-square (rms) deviation of $\pm 0.014 \mathrm{~kg} \mathrm{~m}^{-3}$ ] and a mean depth of $30 \pm 1.4 \mathrm{~m}$ (Figs. 5 and 6 ). The dye release was accompanied by deployment of nine GPS-tracked drifters drogued at $30 \mathrm{~m}$, in a cross pattern, and a Lagrangian float at the center of the streak (Fig. 6). Simultaneously, a swarm of 18 EMAPEX floats forming three concentric circles (1-, 2-,

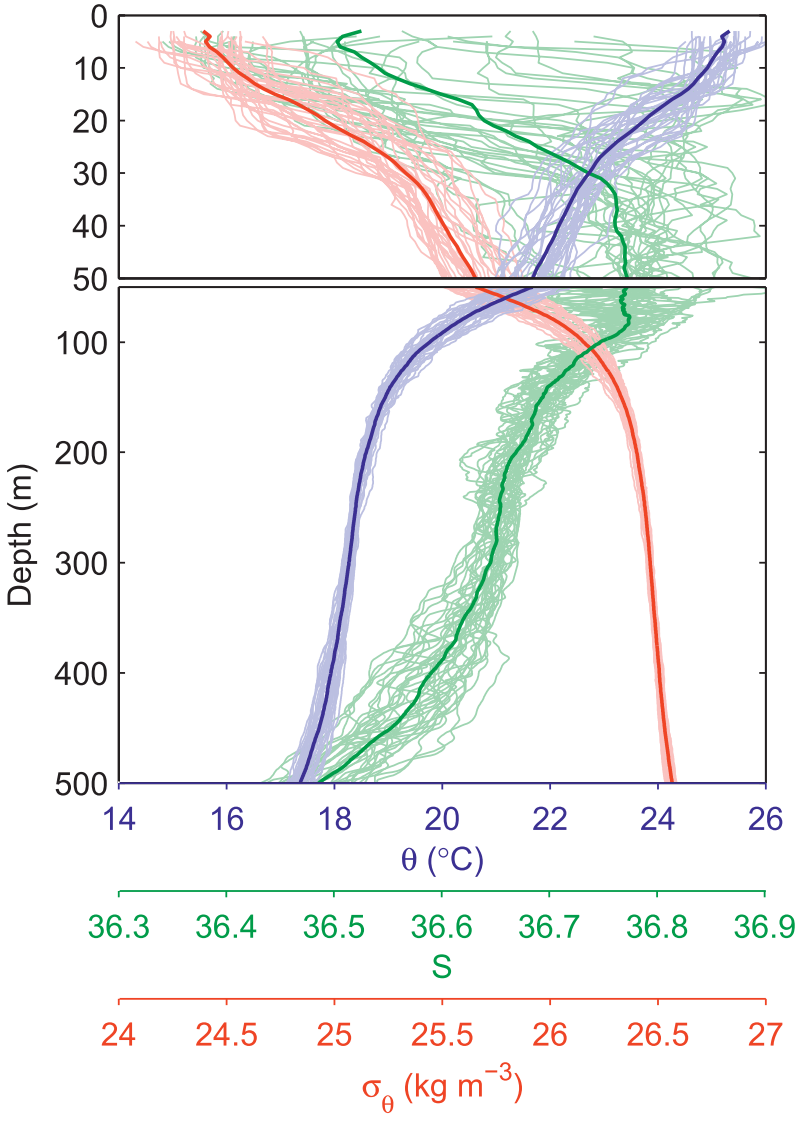

Fıg. I. Profiles of potential temperature (blue), salinity (green), and potential density (red) during LatMix Seaglider deployment (3-10 Jun 20II). Heavy lines indicate the mean profiles. Salinity is reported on the practical salinity scale throughout (nondimensional).

\section{SUPPLEMENTAL MATERIAL}

A Google Earth interactive map of shipboard, Aautonomous, and airborne surveys during the summer 20II LatMix experiment is available online as supplemental material (http://dx.doi.org/I0.II75/BAMS-D-I4-000I5.2).

To explore these maps, you need Google Earth viewer installed on your computer. The software is free and could be downloaded online (from https://www.google.com learth/). A user guide is available online as well (at http:// earth.google.com/userguide/).

Download the LatMix20 I I KMZ file to your computer and double-click it to open it in Google Earth; LatMix20 I I. kmz will appear under the "Temporary Places" as shown in the illustration below.

A good place to start exploring the interactive maps is the "LatMix 20II tour," which will animate the timeline of the experiment. Entries in the "Calendar" folder would allow you to focus on a particular day of the experiment. Visibility of SST layers as well as the tracks of the individual instruments can be controlled with the corresponding checkboxes. 

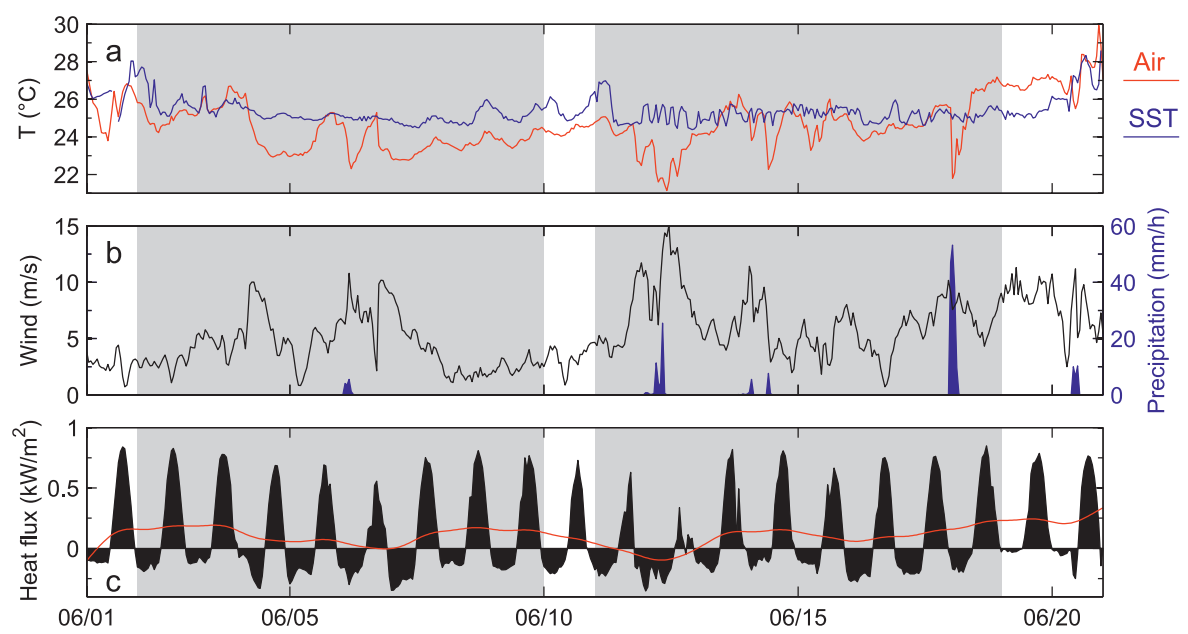

FIG. 2. Air-sea interface conditions in the LatMix area based on R/V Endeavor observations. Shown are (a) air (red) and sea surface (blue) temperatures; (b) wind speed (black) and precipitation rate (blue); and (c) net instantaneous (black) and low-passed (red) air-sea heat flux [positive into the ocean (i.e., warming)]. Shading indicates the periods of the weak-straining (2-10 Jun; see also Figs. 4-7) and moderate-straining (II-I9 Jun; see also Figs. 8-I2) studies. face of this confluence implied an isopycnal diffusivity on the order of $1 \mathrm{~m}^{2} \mathrm{~s}^{-1}$ at the $1-5-\mathrm{km}$ scales of the dye patch.

Tracking the spreading of the array of drogued drifters provided an alternative measure of lateral (but not isopycnal) dispersion. The change in meansquare separation between the nine drogued drifters over the 6-day period gave an upper bound of $0.6 \mathrm{~m}^{2} \mathrm{~s}^{-1}$ for the effective lateral diffusivity. Moreover, fitting a strain-diffusive model to the second moment of the drifter separation

and $3.5-\mathrm{km}$ nominal diameters) was deployed at the site of the release; on 5 and 7 June, two EM-APEX floats were repositioned and three additional floats were deployed.

Over the next 6 days, culminating on 10 June, the dye and surrounding drifters and floats traveled $30 \mathrm{~km}$ south-southeast while remaining in a relatively compact group (Fig. 6). The outer ring of EM-APEX floats was stretched in the northwest-southeast direction by a factor of 2.8 and compressed by about a factor of 2 in the orthogonal direction. The drifter array showed similar stretching along the same northwest-southeast axis. This relatively weak deformation of the float and drifter arrays and relatively little rotation confirmed that weak-straining $(0.03 f-0.07 f)$, weak-vorticity conditions persisted throughout this case study in the upper $150 \mathrm{~m}$. Over the same period, the rhodamine dye patch was stretched and diffused laterally into a relatively coherent but somewhat distorted $12 \mathrm{~km} \times$ $5 \mathrm{~km}$ ellipse (Fig. 6). The weak diapycnal spreading of the patch (Fig. 7) corresponded to a diapycnal diffusivity of less than $10^{-5} \mathrm{~m}^{2} \mathrm{~s}^{-1}$.

Stretching of the dye patch in the direction of the major axis of the deformation tensor implied an alongstreak strain rate on the order of $3 \times 10^{-6} \mathrm{~s}^{-1}(0.04 f)$. This along-streak stretching presumably was balanced by a confluence along the orthogonal axis, as evidenced by the convergence of the drifters in the cross-streak direction. Assuming Fickian diffusion and a steadystate balance between confluence and diffusion, the spread of dye in the cross-streak direction in the gave a best estimate of lateral diffusivity of $0.2 \mathrm{~m}^{2} \mathrm{~s}^{-1}$, while the strain rate estimate was in agreement with that mentioned above $\left(3 \times 10^{-6} \mathrm{~s}^{-1}\right.$ or $\left.0.04 f\right)$ (J. Early 2015, manuscript in preparation). This factor of 5 discrepancy in the lateral diffusivity estimates may reflect the differences between dispersion of dye and of drifters: while the dye measures true isopycnal dispersion, the drifters respond to the velocity at the fixed depth of their drogues, which may not have a fixed potential density. Therefore, drifter estimates of dispersion may not always accurately represent the dispersion of tracers.

Short nighttime fluorescein releases were performed on 5, 8, 9, and 10 June. These releases were accompanied by deployment of a second Lagrangian float and three drogued drifters. The fluorescein patches were mapped by R/V Cape Hatteras between or during continued surveys of the rhodamine patch. The fourth fluorescein patch of this set (10 June) was the first one surveyed by airborne lidar.

Moderate-straining study. A saddle point in the flow on the periphery of an $O(100) \mathrm{km}$ mesoscale eddy was chosen as the initial location for the moderate-straining case study of 12-20 June 2011 (Fig. 8). A chain of such corotating cyclonic (counterclockwise) eddies appeared to be forming in secondary instability of a larger Gulf Stream meander (Figs. 4 and 8). The saddle point occurred at the edge of a warm, relatively fresh, anticyclonic (clockwise) filament from the eddy intruding into a cooler and saltier northward-flowing filament. 
Underneath the surface thermohaline front visible at the stagnation point (Fig. 8) was an upper-pycnocline front of the opposite sense, with saltier, denser, and somewhat cooler water to the west (Fig. 9a, I-IV). High-resolution data from the MVP surveys by R/V Endeavor found salinity differences as high as 0.3 on isopycnal surfaces in the vicinity of this front (Fig. 10). Consistent with the reversal of density gradients below the mixed layer, maximum northward flow exceeding $0.4 \mathrm{~m} \mathrm{~s}^{-1}$ occurred at middepth $(40 \mathrm{~m})$. Kilometer-scale strain rates associated with the front reached $0.5 f$.

The early evolution of the upperpycnocline thermohaline front prior to and immediately after the dye release (12-15 June) is shown in Fig. 10 in isopycnal coordinates. Initially spanning several kilometers, the width of the front sharpened to $O(100) \mathrm{m}$ over the course of 4 days

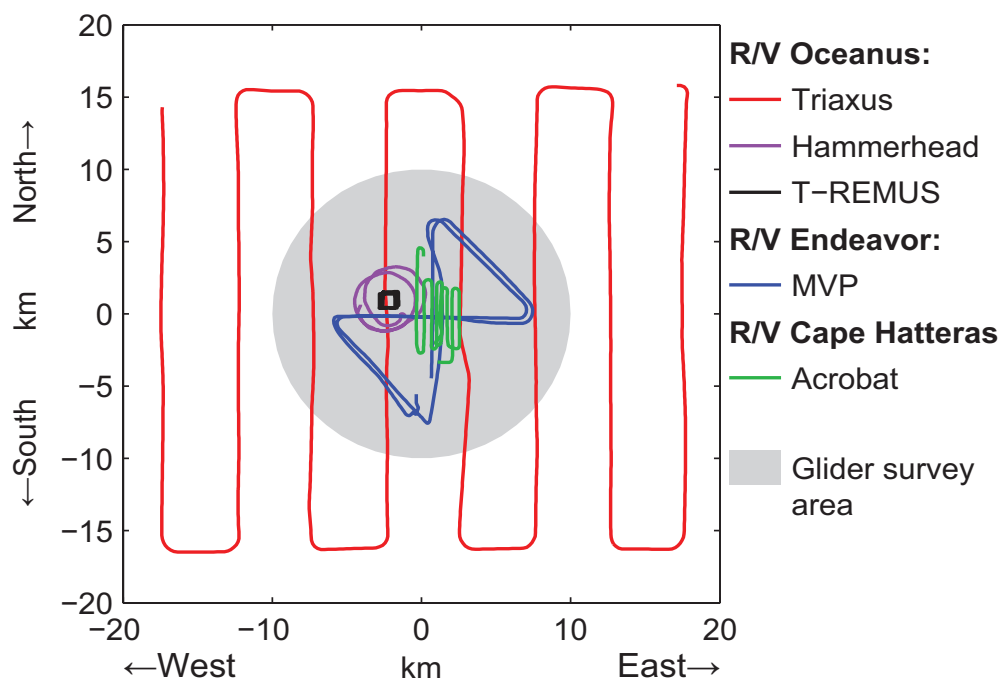

FIG. 3. Illustration of the nested sampling from R/V Oceanus (Triaxus, Hammerhead, and T-REMUS), R/V Endeavor (MVP), and R/V Cape Hatteras (Acrobat). Triaxus measured along a $30-\mathrm{km}$ radiator grid (red), MVP made repeated $15-\mathrm{km}$ bowtie surveys (blue), Acrobat performed adaptive surveying of the dye with a $3-\mathrm{km}$ radiator grid, and Hammerhead was towed in 2-km-radius circles (magenta) around I-km T-REMUS boxes (black) centered on a drogued Gateway buoy (not shown). Gliders surveyed within the $10-\mathrm{km}$-radius area on multiple intersecting tracks. Subsequent sampling patterns were shifted to keep up with the advection of dye and drifters.

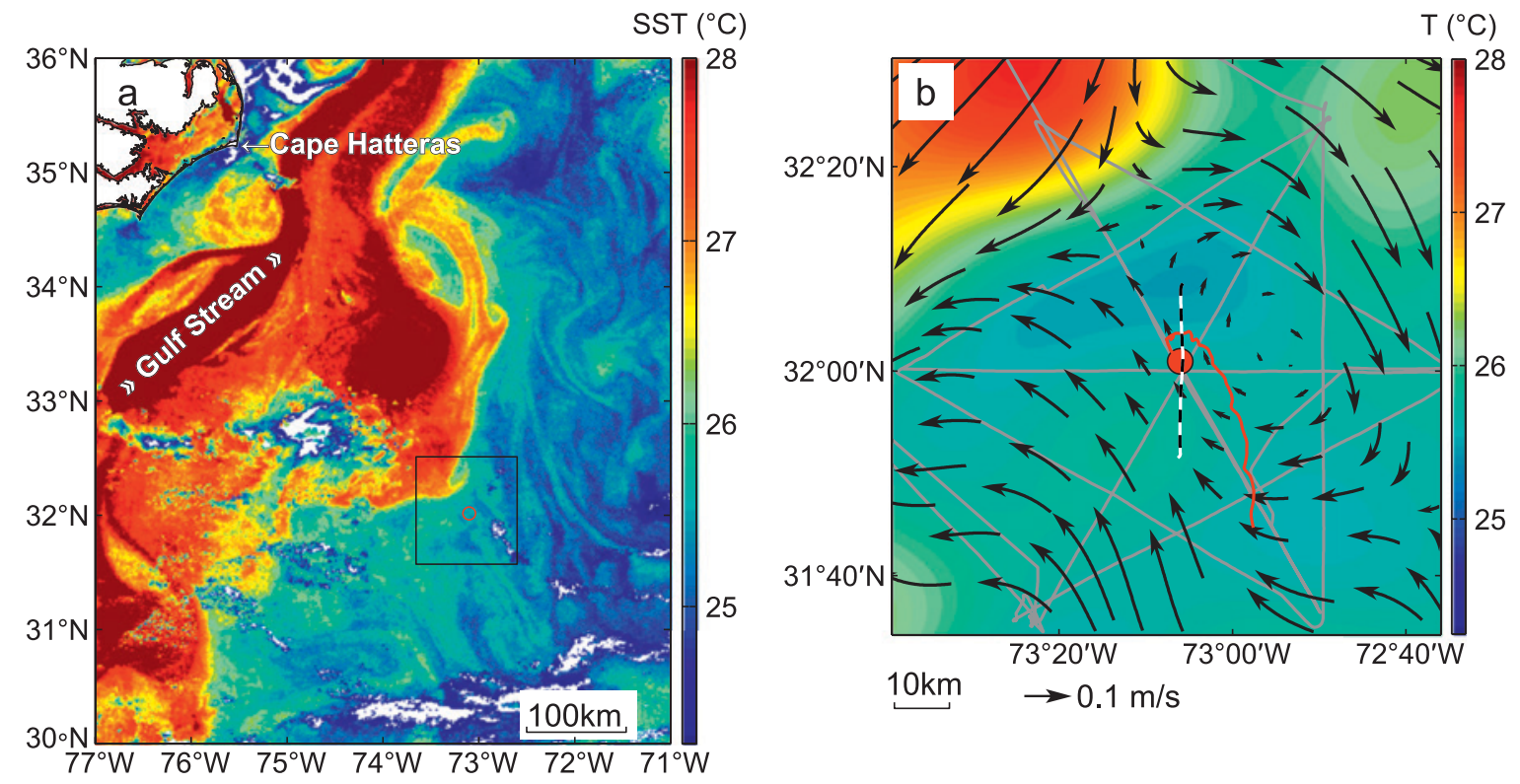

FIG. 4. Weak-straining study area prior to the dye release on 4 Jun $20 I$ I. (a) AVHRR sea surface temperature image. (b) Sea surface temperature and velocity field objectively interpolated from the observations during the mesoscale reconnaissance survey carried out by all three vessels on 2 and 3 Jun $201 \mathrm{I}$ (ship tracks are shown as gray lines); the map extent is shown with a black square in (a). The red circle marks the site of the drifting array deployment and rhodamine dye release. The red line in (b) shows the drift of the array between 4 and 10 Jun 20 I I (see also Fig. 6). The east-west offset in (b) between the array drift track and the flow pattern is likely due to evolution of the flow between the time of the map and the longer period of the drift. Meridional transect along the dashed line is shown in Fig. 5. 

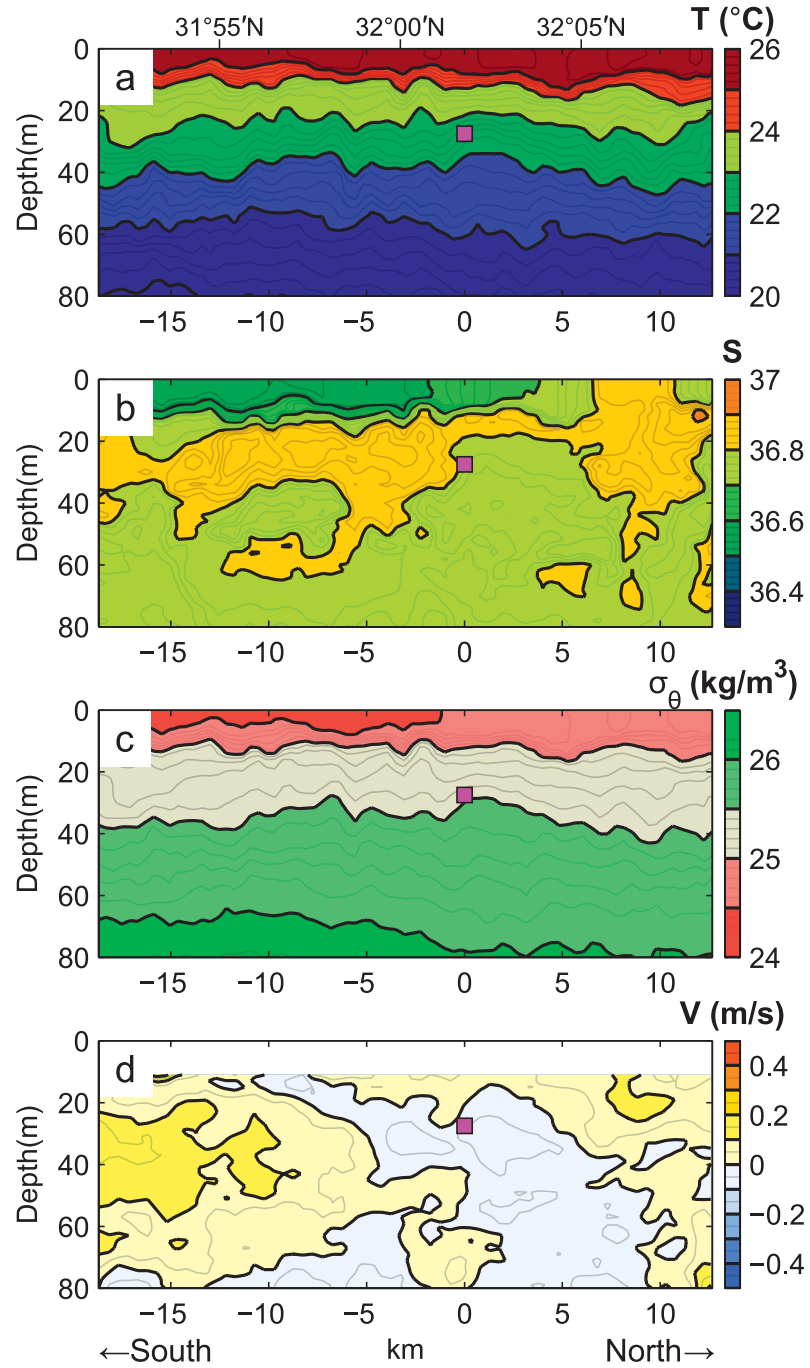

as a result of confluence on the order of $0.1 f$. This sharpening was not monotonic in time because of significant near-inertial vertical shear that tilted isohalines.

Rhodamine was released for the moderate-straining study on 13 June along a $2-\mathrm{km}$-long line oriented about $20^{\circ}$ from true north (Fig. 11). The mean potential density at the release was $25.04 \pm 0.011 \mathrm{~kg} \mathrm{~m}^{-3}$ (vertical

Fig. 5 (LEFT). Meridional sections of (a) temperature, (b) salinity, (c) potential density, and (d) zonal velocity through the weak-straining study site, based on the Triaxus and shipboard ADCP data from R/V Oceanus on 4 Jun 20ll. The magenta rectangle marks the approximate location of rhodamine dye release. The section location is marked with a dashed line in Fig. $4 \mathrm{~b}$.

Fig. 6 (BELOW). Evolution and advection of the rhodamine dye patch and the arrays of drifters and floats during the weak-straining study (4-10 Jun 20II). (left) The rhodamine patch (magenta), the trajectories of the centers of mass of the drifter array (red) and EMAPEX array (blue), and the interpolated trajectory of the Lagrangian float (green). The sites of rhodamine and fluorescein releases are marked with magenta and cyan triangles, respectively. (right) The configuration of the arrays at the beginning of the study (0700 UTC 4 Jun $20 \mathrm{II})$ and at the end (0000 UTC 10 Jun 20II). The location and extent of each panel is marked on the left with the dashed lines (red for drifters and blue for EMAPEX). North and east distances are relative to the centers of mass of the drifter arrays. A few EM-APEX floats were omitted for clarity. The magenta lines in the 4 Jun panels show the initial rhodamine dye streak.
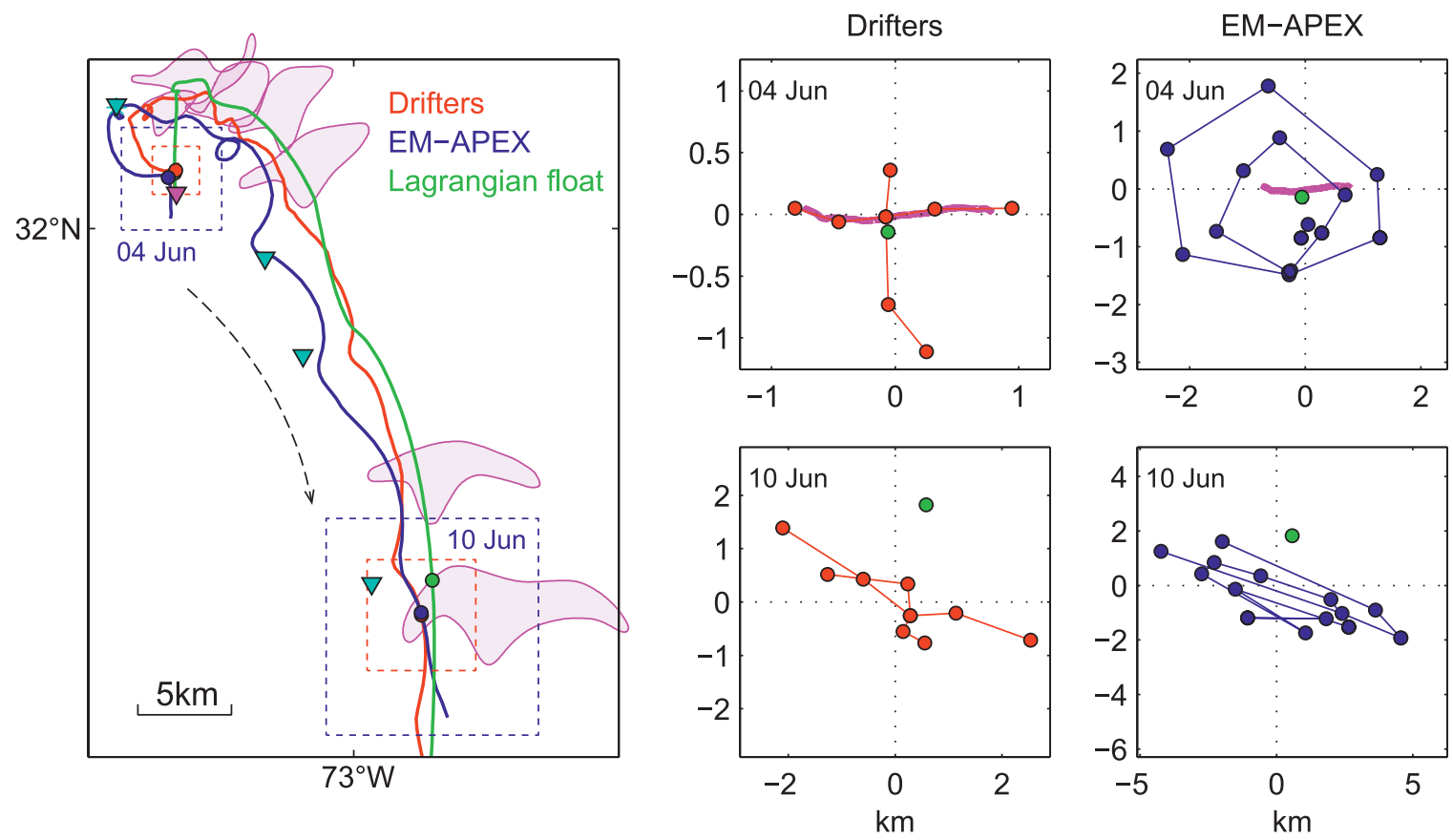
potential density gradient $\approx-0.04 \mathrm{~kg} \mathrm{~m}^{-4}$ ) and mean depth approximately $30 \pm 1.1 \mathrm{~m}$, similar to those in the weak-straining case. Again, the dye patch was marked with nine drogued drifters in an approximate cross pattern and a Lagrangian float. As before, a swarm of 18 EM-APEX floats in three concentric circles (1-, $2-$, and $4-\mathrm{km}$ nominal diameters) was also deployed (Fig. 11).

The dye patch and drogued drifters were entrained in the northward branch of the flow, accelerating to $0.4 \mathrm{~m} \mathrm{~s}^{-1}$ by 14 June. In contrast, northward progress of the EM-APEX floats lagged substantially as a result of strong vertical shear experienced by the floats, since they cycled between the surface and 150-m depth (see appendix). By 16 June, separation between the dye patch and the EM-APEX swarm grew to almost $55 \mathrm{~km}$, straining surveying resources. At the same time, the swarm also stretched into a narrow $20-\mathrm{km}$-long line, so it could no longer provide adequate spatial coverage for estimates of vorticity. As a consequence, on 17 June, all EM-APEX floats were recovered and redeployed $10 \mathrm{~km}$ downstream of the dye patch in a similar but enlarged pattern of concentric circles (2.5-, 5-, and 10-km nominal diameters).

During the moderate-straining case study, a rich structure of submesoscale strands became evident in survey transects, most noticeable in the salinity field (Fig. 9b, II). To what extent these features represented spatial variability in the front versus temporal evolution is not known. Sea surface temperature (SST) imagery (Fig. 12b) suggests fragmentation and warming of the cold filament at the surface. However, the subsurface northward jet advecting the dye and drifters remained coherent and strengthened to $>0.5 \mathrm{~m} \mathrm{~s}^{-1}$ (Fig. 9b, IV). The dye patch was also unaffected by this fragmentation and remained a coherent continuous streak. By the end of the study, the along-stream extent of the dye patch exceeded $50 \mathrm{~km}$, so daily rhodamine surveys were limited to its north end.

By the end of the second study (17-20 June), the cold filament formed a mushroom-like feature strained by a pair of counterrotating mesoscale eddies (Fig. 12c). The subsurface jet split into several

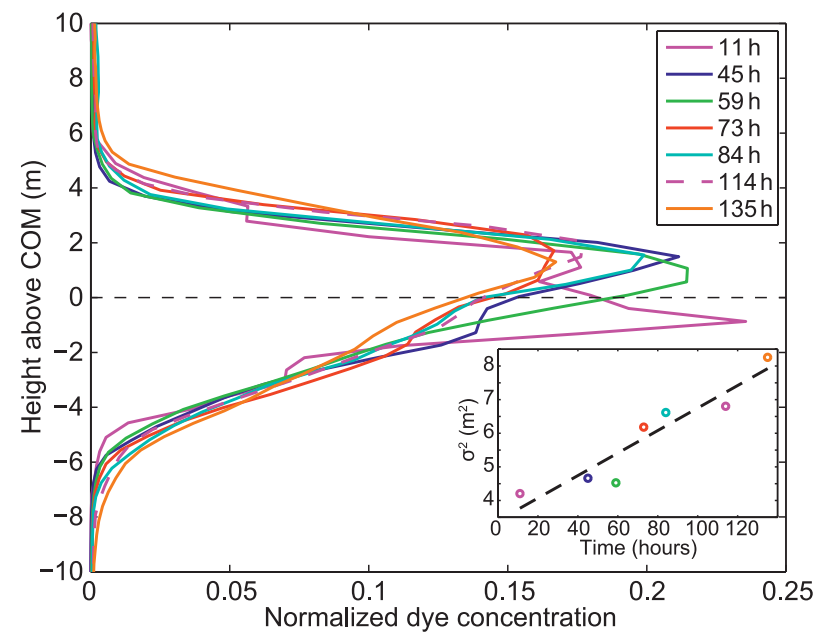

FIG. 7 (RIGHT). Evolution of the normalized mean distribution of rhodamine concentration as a function of height above the dye center of mass during the weakstraining case study shown in Fig. 6. The key gives the time since release. The inset shows the increase of the second moment of dye concentration as a function of time, revealing the weak vertical broadening of the dye patch. The least-squares linear fit (dashed line) corresponds to a diapycnal diffusivity of $5 \times 10^{-6} \mathrm{~m}^{2} \mathrm{~s}^{-1}$.

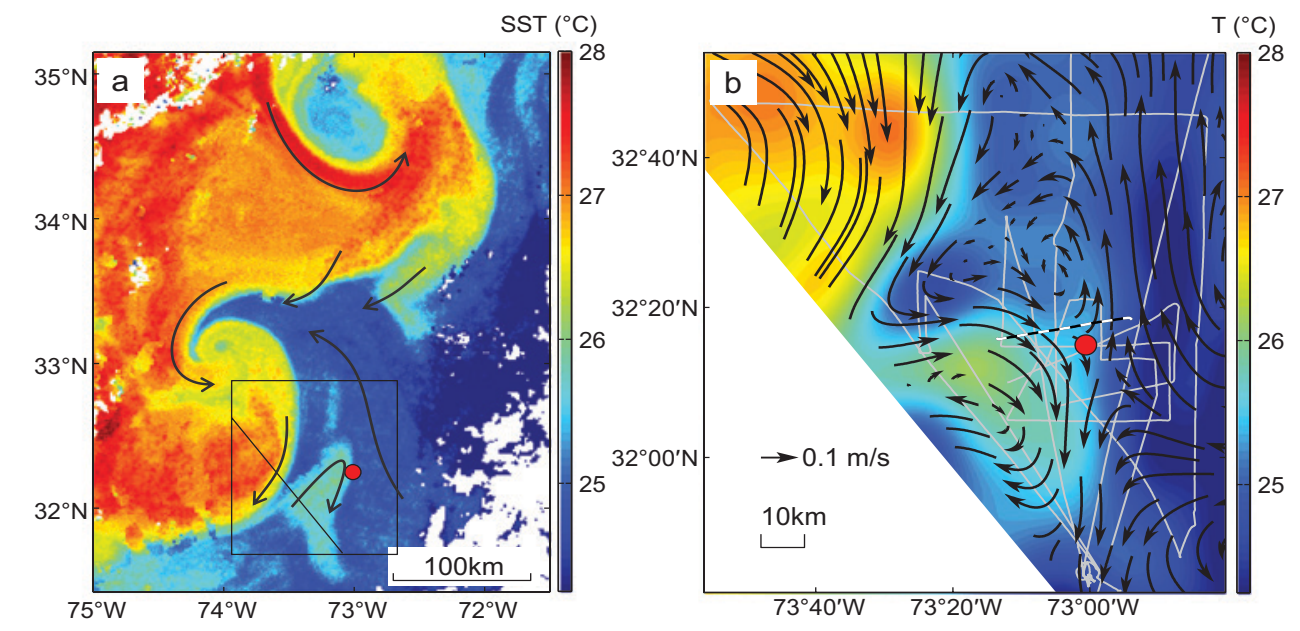

Fig. 8. Moderate-straining study area prior to the 13 Jun dye release. (a) AVHRR sea surface temperature image; black arrows show a subjective interpretation of the surface flow pattern. (b) Sea surface temperature and velocity field based on the reconnaissance survey carried out by all three vessels between 10 and 12 Jun 2011 (ship tracks are shown as white lines); the map extent is shown in (a). Red dots mark the flow stagnation (hyperbolic) point targeted by the study (see also Fig. II). Zonal transect along the dashed line is shown in Fig. 9a. 
cores and decelerated, while the vertical shear increased (Fig. 9c, IV). The sharp salinity fronts in the upper pycnocline disappeared (Fig. 9c, II). A series of slanted thermohaline interleaving features (intrusions) formed at 40-80 m (Fig. 9c, I-II), possibly a signature of submesoscale frontal instabilities that led to restratification and fragmentation of the front (Shcherbina et al. 2010). The drifters, Lagrangian float, and EM-APEX swarm slowed and dispersed in response to increased vertical shear (Figs. 11, and 12c). The surveyed part of the rhodamine dye patch broadened in the cross-stream direction while its along-stream extent remained in excess of $55 \mathrm{~km}$.

In spite of the stronger background currents characterizing the moderate-strain case, diffusivities inferred from the dye were similar to those for the weak-straining case: namely, a diapycnal diffusivity of less than $10^{-5} \mathrm{~m}^{2} \mathrm{~s}^{-1}$ and a $1-5-\mathrm{km}$ isopycnal diffusivity on the order of $1 \mathrm{~m}^{2} \mathrm{~s}^{-1}$ (again assuming a Fickian diffusivity and a steady-state balance between cross-streak confluence and diffusion). (a) 13 June

(I)

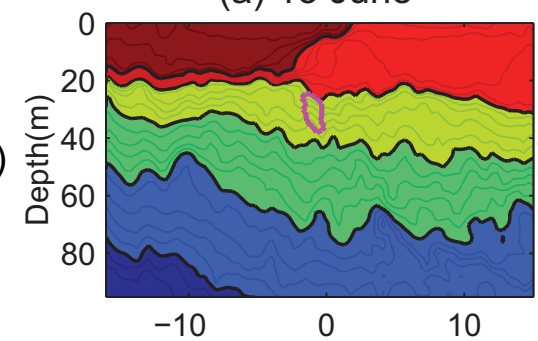

(b) 17 June

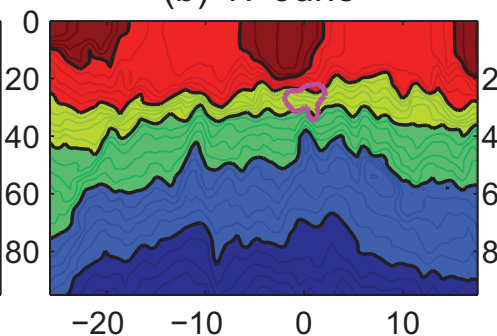

(c) 19 June

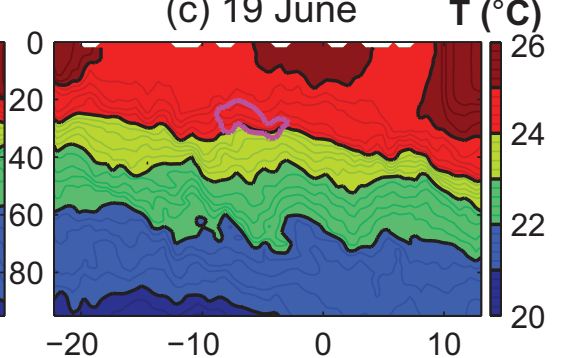

(II)
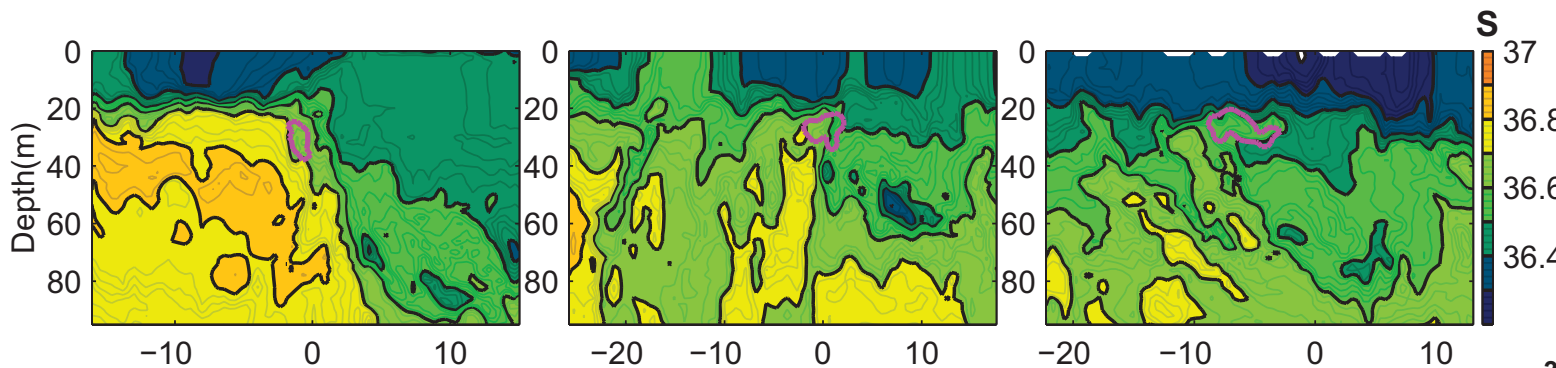

(III)
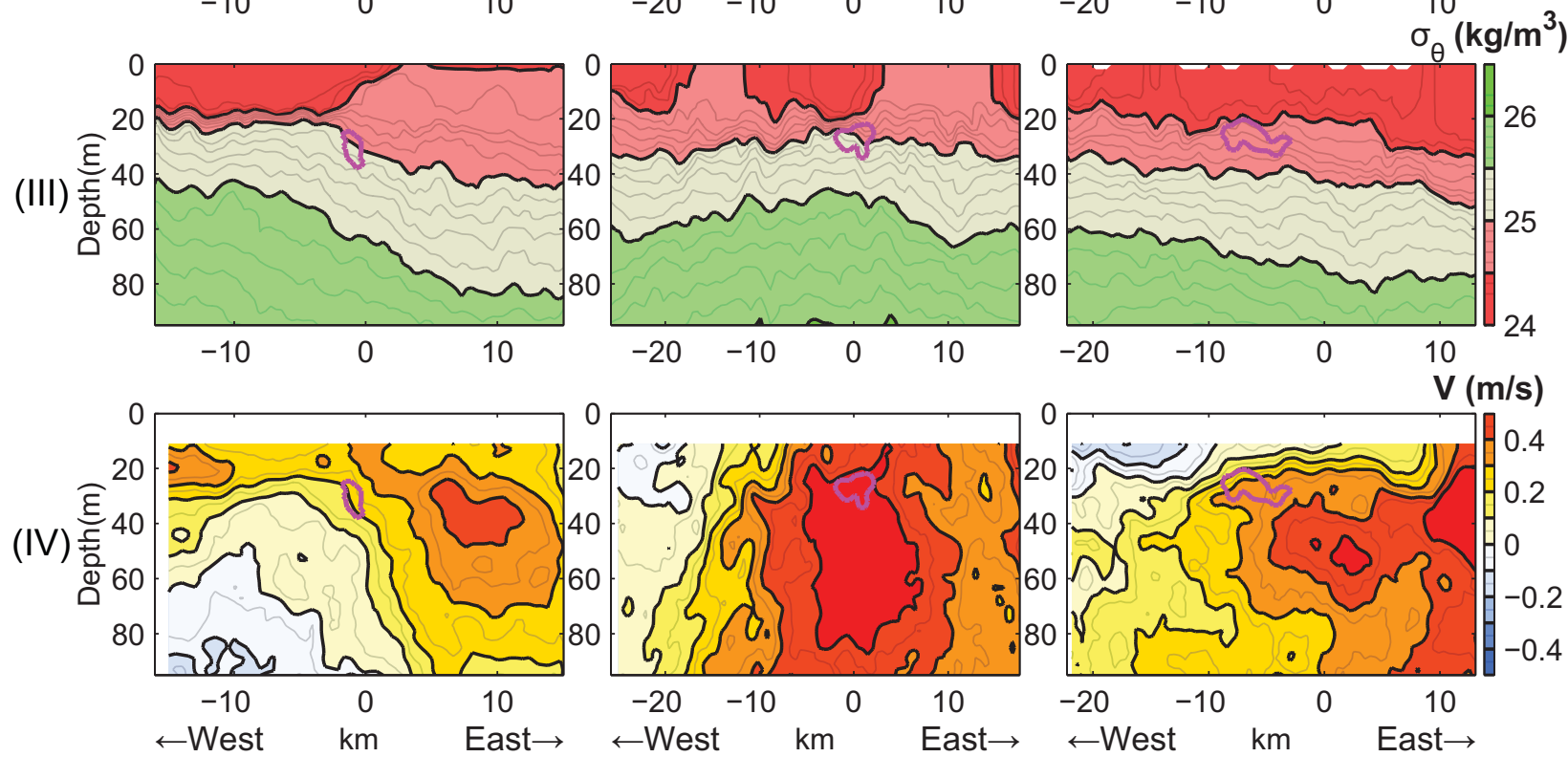

FIG. 9. Zonal sections of temperature (row I), salinity (row II), potential density (row III), and meridional velocity (row IV) during the moderate-straining case study based on Triaxus and shipboard ADCP surveys at approximately (column a) 1900 UTC I3 Jun, (column b) 0500 UTC 17 Jun, and (column c) 1240 UTC 19 Jun. The magenta contour shows the evolution of the rhodamine dye patch. The 13 June section location is marked with a dashed line in Fig. 8b; other sections were similarly positioned in the frame of reference advecting with the drifters. The distances are eastward relative to the center of mass of the drifter array. 
During the moderate-straining study, short nighttime fluorescein dye releases were performed along the drift track on 15, 16, and 18 June (one to the east and two to the west of the main rhodamine streak). The first two fluorescein patches were surveyed by R/V Cape Hatteras, the T-REMUS autonomous vehicle, and airborne lidar (airborne surveys of the last fluorescein patch were prevented by a line of energetic thunderstorms that passed over the experimental site for several hours while the aircraft stood by).

Lidar studies of kilometer-scale dye dispersion. As with laboratory dye experiments, details of dispersion processes are best studied before different parts of the dye patch overlap with one another. Furthermore, one wants a time series of synoptic views of the dye as it evolves: something very difficult to obtain from a research vessel with towed instruments. Thus, the experimental program included rapid surveys with airborne lidar (see appendix for details). The lidar system used was tuned to the absorption and emission bands of fluorescein. Hence, relatively short-duration fluorescein dye-release experiments were done simultaneously and in close proximity in depth and location to the rhodamine experiments. The lifetime of fluorescein is short in sunlight and the insolation at the study site is strong, so the releases were done at dusk and the flights took place that same night, with the plane on site for up to 6 hours. The fourth fluorescein release during the weak-straining case study and the first two fluorescein releases during the
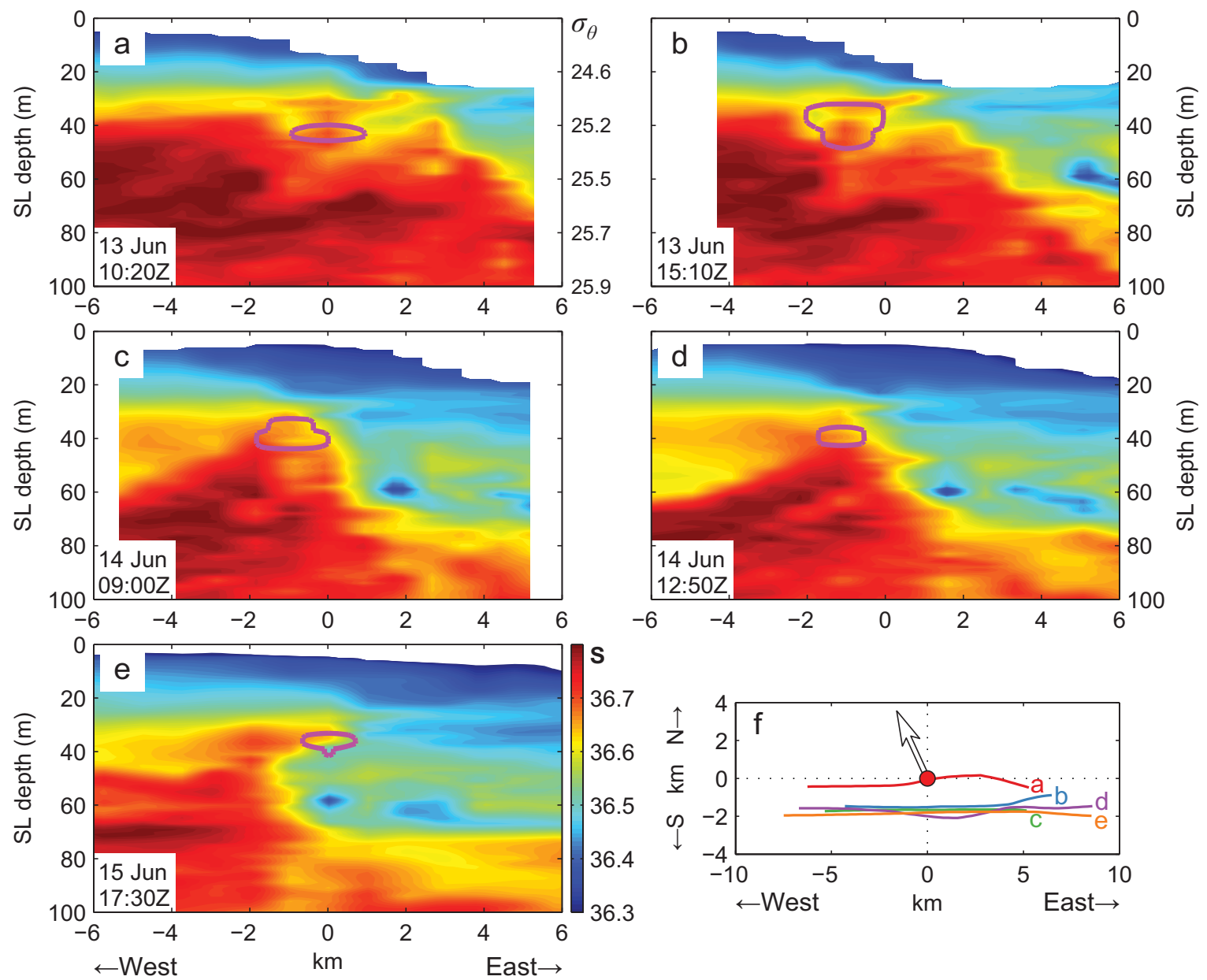

FIG. 10. (a)-(e) High-resolution zonal MVP sections showing evolution of a north-south-oriented thermohaline (spice) front in the vicinity of the rhodamine dye patch between 13 and 15 Jun 20 II under a $\sim 0$. If confluence. The vertical axis is an isopycnal (semi-Lagrangian) depth: namely, the average depth of an isopycnal, and corresponding potential density values are marked on the right in (a). The magenta contour shows evolution of the rhodamine dye patch. (f) Location of sections shown in (a)-(e) in the advected frame of reference moving with the center of mass of the drifter array (red circle). The arrow shows the mean advection direction during the $13-15$ Jun period. 
Drifters

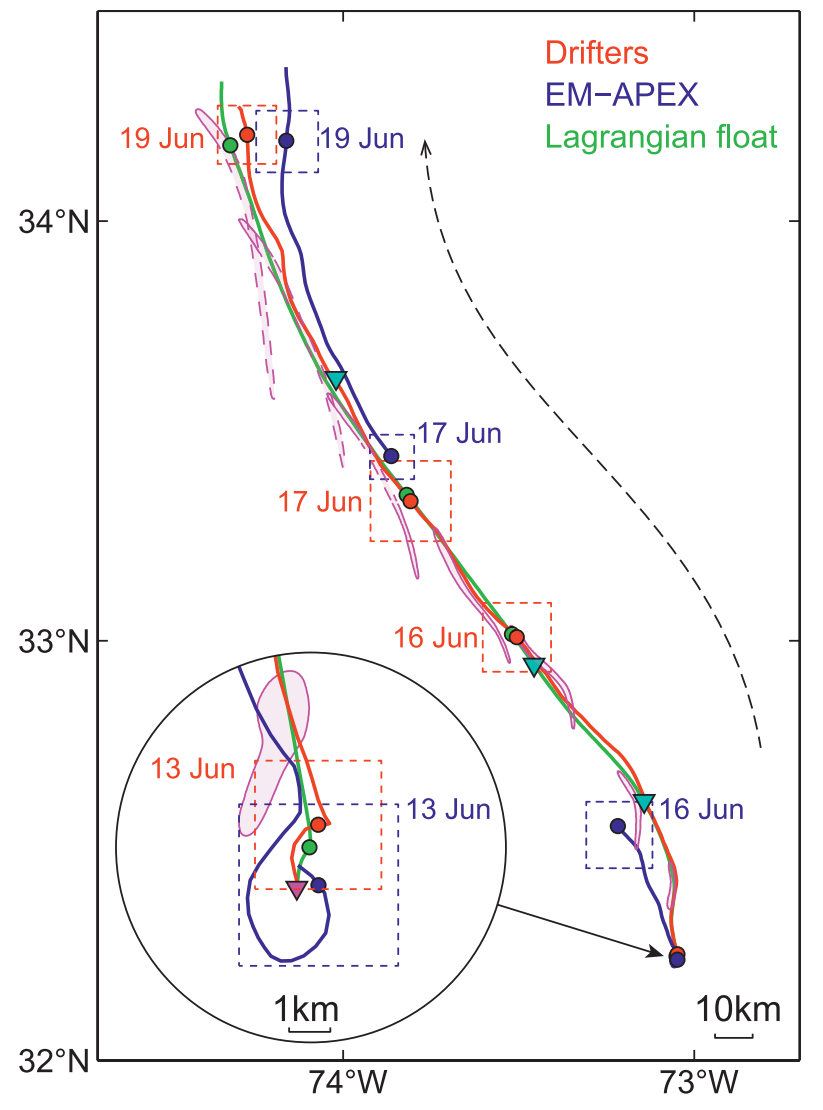

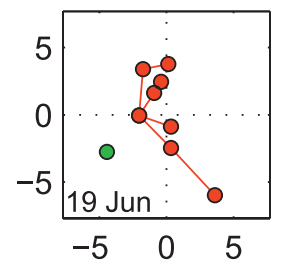
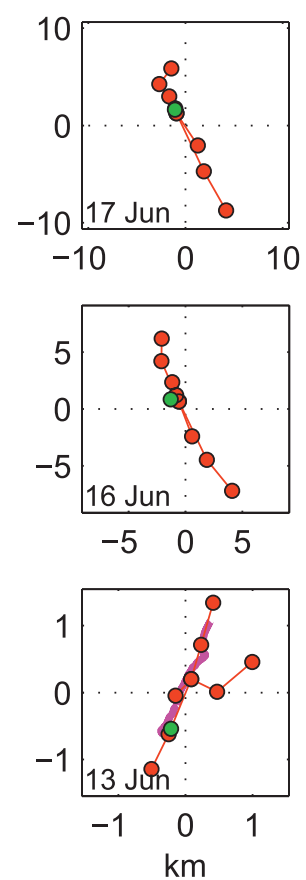

EM-APEX
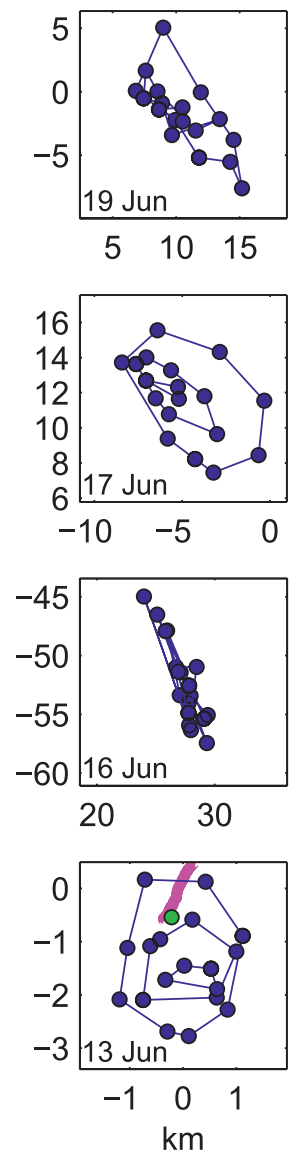

FIG. II. Evolution and advection of the rhodamine dye patch and the arrays of drifters and floats during the moderate-straining study of 13-20 Jun 20II. (left) Rhodamine patch (magenta) and the trajectories of the centers of mass of the drifter array (red) and EM-APEX array (blue) and the interpolated trajectory of the Lagrangian float (green). The sites of rhodamine and fluorescein releases are marked with magenta and cyan triangles, respectively. Dashed contours show the estimated extent of the unsurveyed dye patch portions. (right) Configurations of the arrays at the beginning of the study (0900 UTC I3 Jun 20II), before and after EM-APEX array redeployment (0700 UTC 16 Jun and 0700 UTC 17 Jun 20II), and at the end of the study (1000 UTC 19 Jun 20II). The location and extent of each panel is marked on the left with the dashed lines (red for drifters and blue for EM-APEX). North and east distances are relative to the centers of mass of the drifter arrays. The magenta lines in the 13 Jun panels show the location and extent of the initial rhodamine dye streak.

moderate-strain study were successfully surveyed by airborne lidar. An impromptu fluorescein release at the surface on 16 June was surveyed with the airborne lidar, showing the evolution of the dye distribution in the mixed layer over the first couple of hours. All of the fluorescein patches were surveyed with the towed instruments from R/V Cape Hatteras.

The lidar surveys showed multiple instances of sinuous meanders of the patches in the first few hours of their evolution, and evidence of filamentation along their peripheries. Such features suggest the presence of weak small-scale $(<1 \mathrm{~km})$ differential lateral advection acting on the patches, possibly contributing to the enhanced dispersion seen at later times in the rhodamine experiments. Multiple fluorescein releases also exhibited banding of the dye (not shown), which may have been the result of internal waves or an instability mechanism, the details of which are under investigation.

In addition to the aforementioned filamentation, the 15 June fluorescein experiment showed fingerlike structures stretching westward relative to the main patch (Fig. 13). It is believed that these are an artifact of the injection, which was not perfectly along isopycnals but crossed a train of internal-wave crests and troughs corrugating the isopycnal surfaces with a $\sim 40$-m horizontal wavelength. The dye streak was then vertically sheared so that dye on 

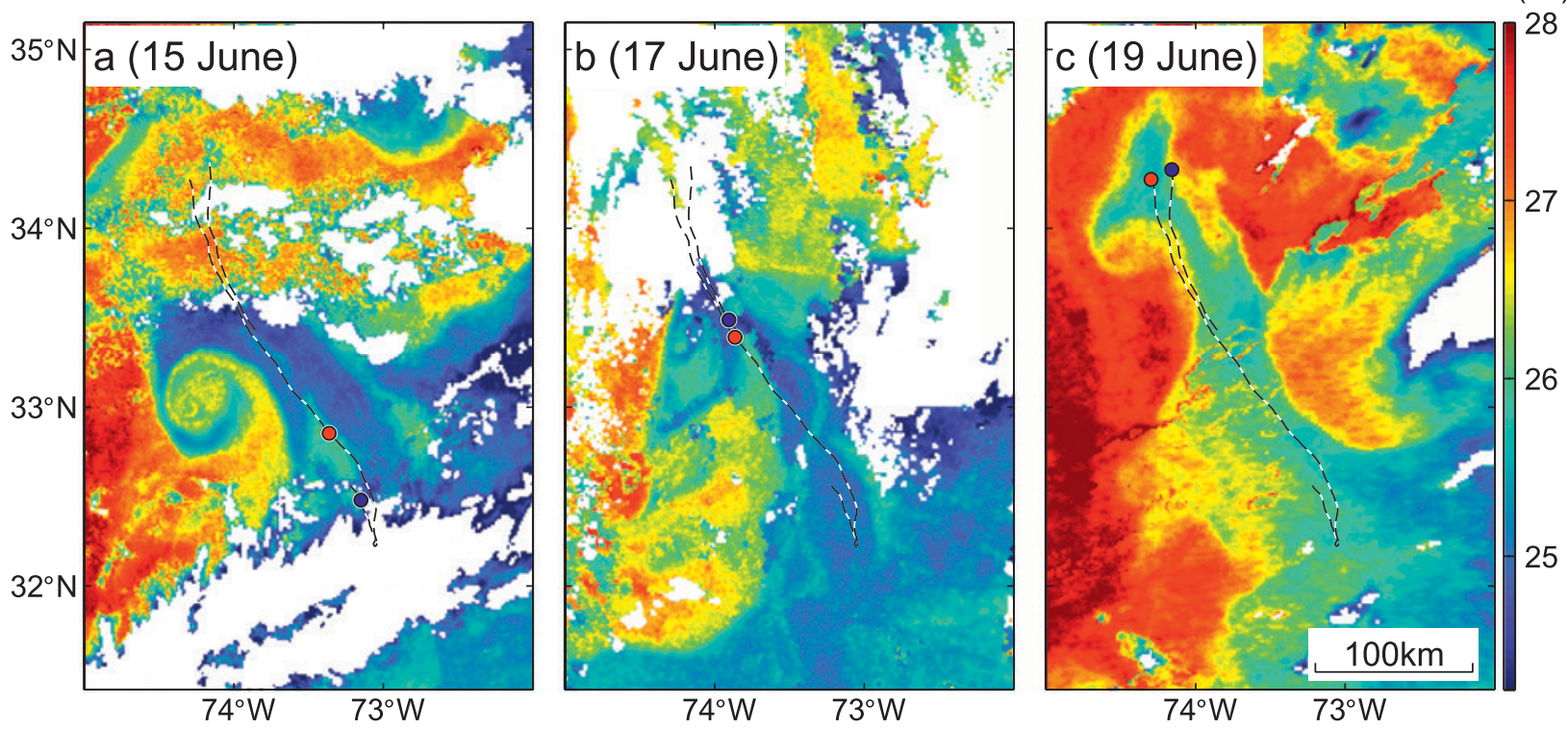

Fig. 12. Evolution of the mesoscale eddy structure encompassing the moderate-straining study 13-20 Jun. AVHRR sea surface temperature imagery on (a) 15, (b) 17, and (c) 19 Jun is shown. Red and blue circles show the locations of the centers of mass of drifter and EM-APEX arrays, respectively, at the time images were acquired. Advection of these arrays over the course of the study (as in Fig. II) is shown with dashed lines.
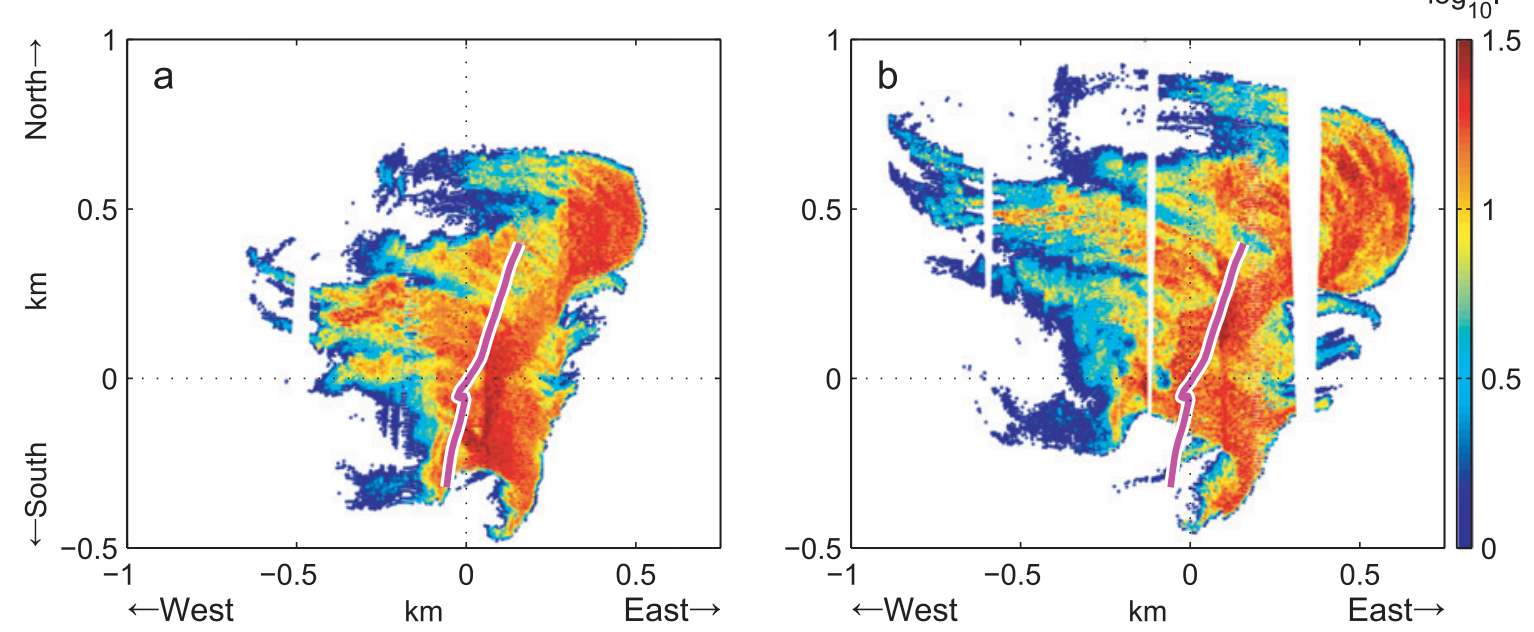

Fig. 13. Lidar view of the fluorescein dye release on 15 Jun 201 I, during the moderate-strain study. Shown is the peak lidar dye return intensity (a) 2.5 and (b) $4 \mathrm{~h}$ after initial dye injection. North and east distances are relative to position of the Lagrangian float deployed with the dye. The magenta lines show the location of the initial dye streak, injected at $29-\mathrm{m}$ depth (potential density of $24.8 \mathrm{~kg} \mathrm{~m}^{-3}$ ).

shallower density surfaces was advected westward relative to deeper layers. That the resulting dye fingers persisted for more than $5 \mathrm{~h}$ after injection despite their relatively small scale suggests that the effective lateral diffusivity acting at the scale of these features must have been weak. Cross-finger confluence, which could potentially help maintain their sharpness, appears to be ruled out because of the approximately constant separation between the fingers. An upper bound on effective horizontal diffusivity across the fingers estimated from scaling gives $K_{h} \lesssim(40 \mathrm{~m})^{2} / 5 \mathrm{~h}=0.1 \mathrm{~m}^{2} \mathrm{~s}^{-1}$ : that is, nearly an order of magnitude smaller than the effective diffusivity estimated at $1-5-\mathrm{km}$ scales. However, $5 \mathrm{~h}$ may not be long enough for the intermittent diapycnal turbulent mixing events that contribute to shear dispersion to have occurred during this interval. Such spatial and temporal intermittency highlights the difficulties 
of describing lateral dispersion in terms of a single effective diffusivity on short time and space scales.

During the 16 June surface mixed layer experiment (not shown), airborne lidar surveys revealed a rich structure of coherent roll vortices, apparently extending to the base of the mixed layer. Within the first $0.25-1.6 \mathrm{~h}$, the patch developed a banded structure oriented in the southwest-northeast direction as it was advected downwind (southwest). The wavelength of the bands was on the order of $100 \mathrm{~m}$. Dye in the bands near the base of the mixed layer appeared to lie upwind of the shallower, more rapidly advected dye. Numerical simulations (Sundermeyer et al. 2014) suggest this banding may have been driven by mixed layer instability associated with a lateral density gradient.

Near-field (meter scale) shear and dye studies. The $O(1)$ m scale structure of the dye immediately after injection was measured by a custom-built Lagrangian float (see appendix for details) deployed in the middle of each fluorescein injection, typically 1-10 $\mathrm{m}$ from the actual streak. The float took about $1 \mathrm{~h}$ to sink to the dye level and was tracked acoustically relative to R/V Cape Hatteras. A temperature sensor and a fluorometer profiled across the $1.2-\mathrm{m}$ height of the float every $30 \mathrm{~s}$ (Fig. 14a). The float was programmed to remain on the injection isopycnal as measured by two sensors on the ends of the float. The float thus measured an approximately $1.2-\mathrm{m}$ high swath of dye and temperature centered on the injection isopycnal. A Nortek Vector velocimeter measured three components of velocity relative to the float at a point about $1 \mathrm{~m}$ below the float's center of buoyancy: that is, effectively measuring 1 - $\mathrm{m}$ vertical shear. The 1000 -s rms velocity, averaged over all deployments, was $15 \pm 4 \mathrm{~mm} \mathrm{~s}^{-1}$, which
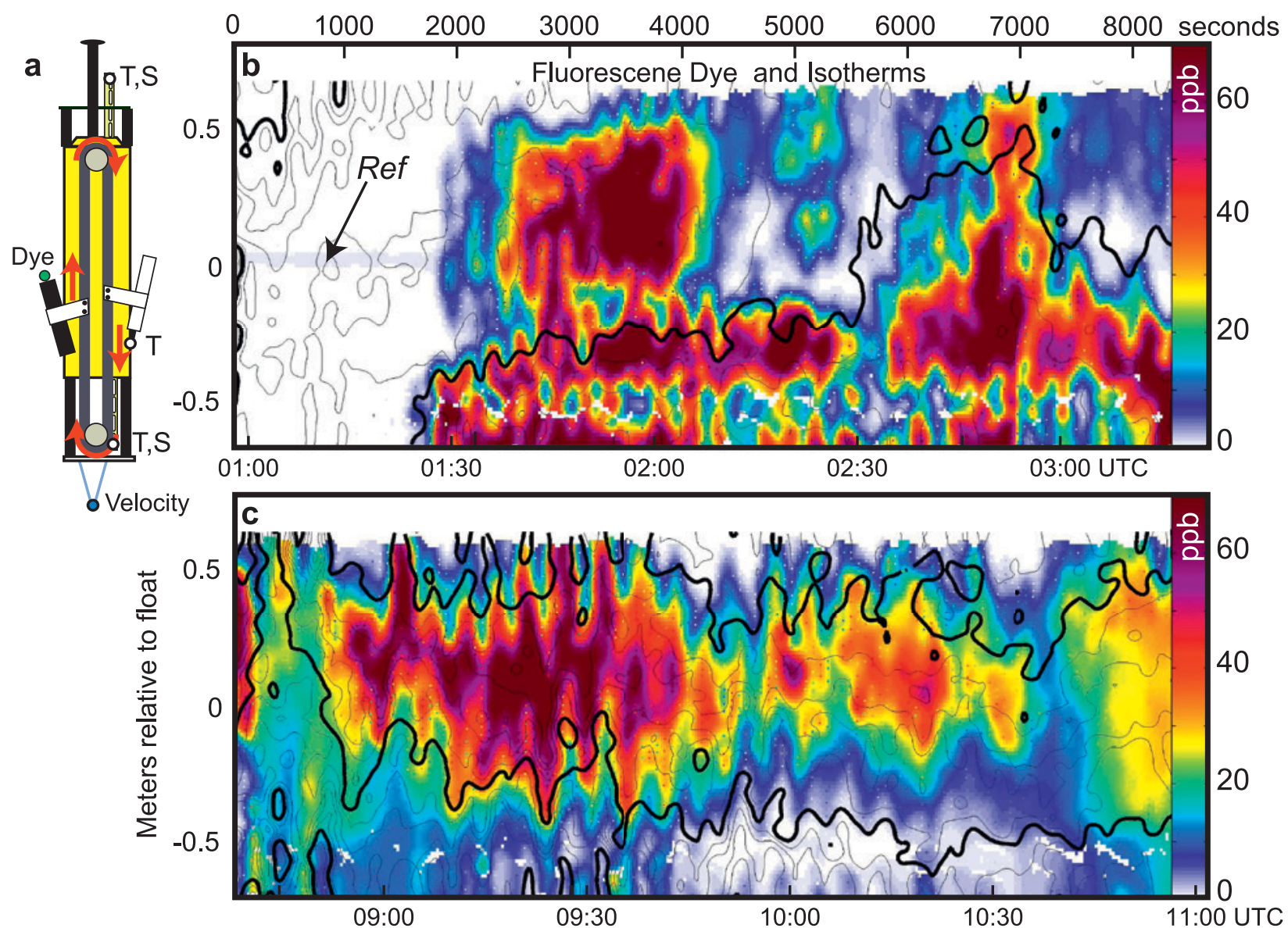

FIG. 14. (a) Cartoon of the Lagrangian float used in near-field dye studies. The float actively changed its buoyancy to straddle the target isopycnal as measured by CTDs on its top and bottom. A chain drive (gray) repeatedly carried dye and temperature sensors across the float's length. A Doppler sonar measured the velocity at a point below the float. (b) Dye (colors) and temperature (contours; heavy contour interval of $0.1^{\circ} \mathrm{C}$; temperature at the center of the float is about $24.23^{\circ} \mathrm{C}$ ) near the start of a float record during the 15 Jun dye release. Mapping is from upcasts of each sensor only. A persistent streak ("Ref") results from a reference mark used to align the sensors. (c) As in (b), but later in the record. The float is drawn to scale relative to the data plots. 
is consistent with internal-wave variability on this scale; the motion of the float relative to the dye was significantly less.

Figures $14 \mathrm{~b}$ and $14 \mathrm{c}$ show two representative swaths of dye and isotherms obtained during the 15 June 2011 fluorescein dye experiment. The float first encountered dye about $1 \mathrm{~h}$ after injection (Fig. 14b). The distribution of dye was highly irregular, changing from greater than $70 \mathrm{ppb}$ to less than $1 \mathrm{ppb}$ in less than $1000 \mathrm{~s}$, corresponding to a distance of only a few meters at a few millimeters per second relative velocity. Figure $14 \mathrm{c}$, taken about $7 \mathrm{~h}$ later on the same deployment, shows a more uniform distribution, with straining of dye and temperature by internal waves, but with nearly as large variations in dye concentrations over a few hours. Such large variations are consistent with visual observations of the dye as it emerged from the injector, which suggested an energetic set of turbulent vortices generated by the injector. Because of this variability, no consistent pattern of dye dilution over the 1-day deployments could be found in the float data.

Separating internal waves from vortices and quantifying turbulent mixing with a swarm of EM-APEX floats. One of the objectives of the summer 2011 LatMix experiment was to separate internal waves from vortical structures (T. Sanford and R.-C. Lien 2015, manuscript in preparation). To do this, it is necessary to observe potential vorticity which, in linearized form, requires observations of the relative vorticity and vortex stretching on spatial scales of $10 \mathrm{~m}-10 \mathrm{~km}$, in coordination with multiple complementary observations. The swarm of EM-APEX floats produced more than 9,000 velocity, temperature, and salinity profiles in the three deployments (see appendix for details). Of these, more than 2,000 vertical profiles included measurements of high-frequency temperature fluctuations using dual thermistors. With the high $120-\mathrm{Hz}$ sampling rate of FP07 thermistor and the vertical profiling speed of the float $\left(\sim 0.15 \mathrm{~m} \mathrm{~s}^{-1}\right)$, the inertial and dissipative subranges of the temperature gradient spectrum were well resolved. The thermal variance dissipation rate $\chi$, turbulence kinetic energy dissipation rate $\varepsilon$, and the vertical diffusivity $K_{v}$ are computed following the method described in Moum and Nash (2009) (Fig. 15).

Internal waves and turbulence in the upper $150 \mathrm{~m}$ were measured by the swarm of EM-APEX floats in both the weak- and moderate-straining case studies, for which the WKB-scaled internal wave energy was $\sim 0.5$ and 0.9 times the canonical internal-wave level in the main pycnocline, respectively (Garrett and Munk 1979). The diapycnal diffusivity inferred at the dye level is $\sim 5 \times 10^{-6}$ and $10^{-5} \mathrm{~m}^{2} \mathrm{~s}^{-1}$ (Fig. 15c). These values are of the same order, if a bit larger than would be expected given the internal-wave field in the main pycnocline from the parameterization of Gregg (1989) and Polzin et al. (1995), and are in agreement with the diapycnal diffusivity inferred from the rhodamine experiments.
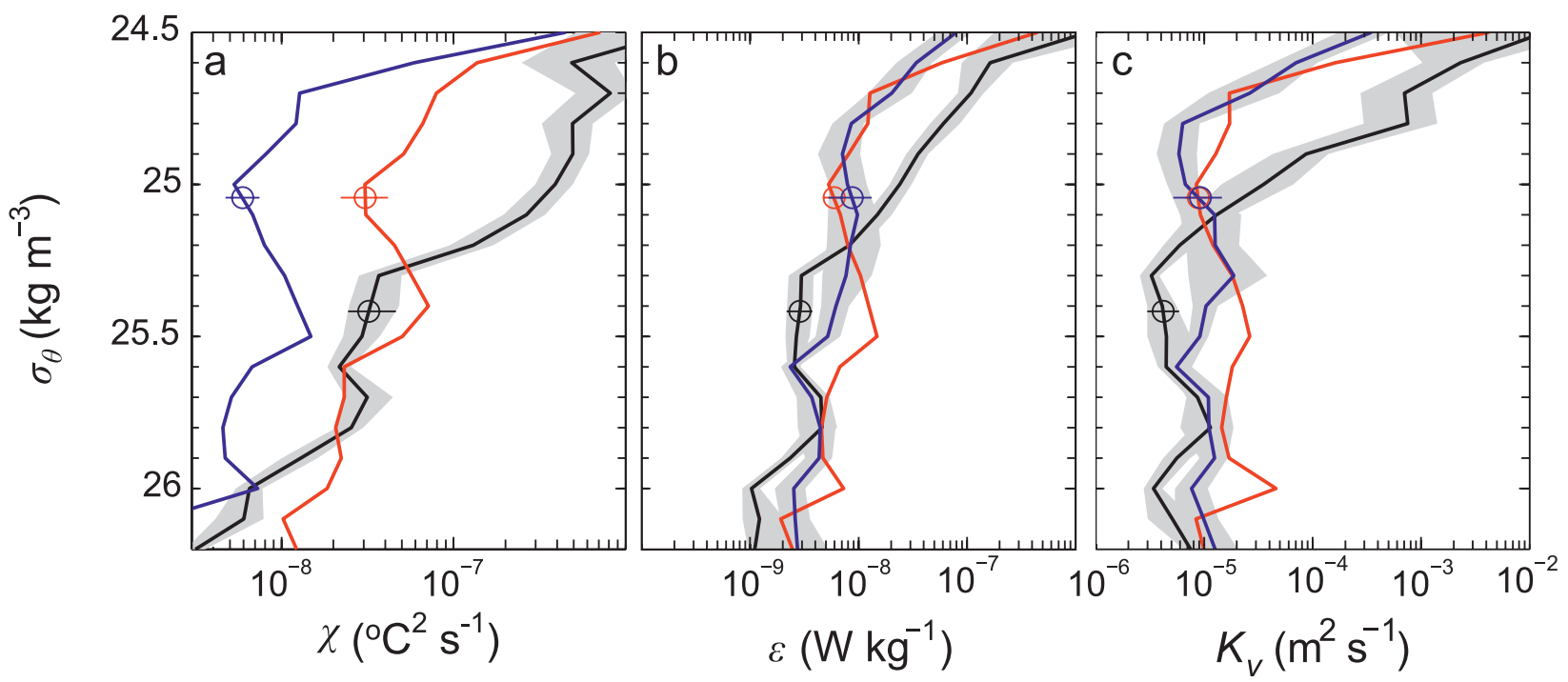

FIG. 15. Average diapycnal profiles of (a) thermal variance dissipation rate, (b) turbulent kinetic energy dissipation rate, and (c) diapycnal eddy diffusivity derived from the three deployments of microstructure EM-APEX floats in weak-straining (3-10 Jun: black) and moderate-straining (12-16 Jun: red; 16-19 Jun: blue) case studies. The shading shows $95 \%$ confidence intervals. The circles and horizontal bars are values and confidence intervals at the target isopycnals of rhodamine dye releases. 
Density and velocity fields measured by the EM-APEX float array allowed direct estimation of the fluctuating part of linear potential vorticity, defined as the sum of relative vorticity $\zeta=v_{x}-u_{y}$ and vortex stretching $-f \partial_{z} \eta$. Here, $\eta=-\rho^{\prime}\left(\partial_{z} \bar{\rho}\right)^{-1}$ is the vertical displacement of isopycnals, calculated from the mean background density profile $\bar{\rho}$ and instantaneous density deviations $\rho^{\prime}=\rho-\bar{\rho}$. Linear potential vorticity variations had rms values of $\sim 0.1 f$ and $\sim 0.5 f$ during the weak- and moderate-straining case studies, respectively, but may include internal-wave advection of background PV gradients. The EM-APEX float measurements promise to provide a means of separating vortical motions from internal-wave motion, as planned.
Glider observations. Four gliders were deployed in each case study, performing separate $12-\mathrm{km}$-long transects relative to the drifting array (Fig. 16d), to characterize the variability of thermohaline properties and turbulent microstructure (see appendix for details). During the moderate-straining experiment, glider observations revealed an abundance of structure in the temperature, salinity, and temperature variance dissipation $(\chi)$ fields (Figs. 16a-c) along the subsurface thermohaline front at 35-65-m isopycnal depth $\left(\sigma_{\theta}=25.0-25.5 \mathrm{~kg} \mathrm{~m}^{-3}\right)$. A higher level of temperature variance dissipation was associated with the warmer, saltier interleaving features in the vicinity of the front (Fig. 16e). Below this interleaving region, there was a pronounced layer of small-scale low-salinity
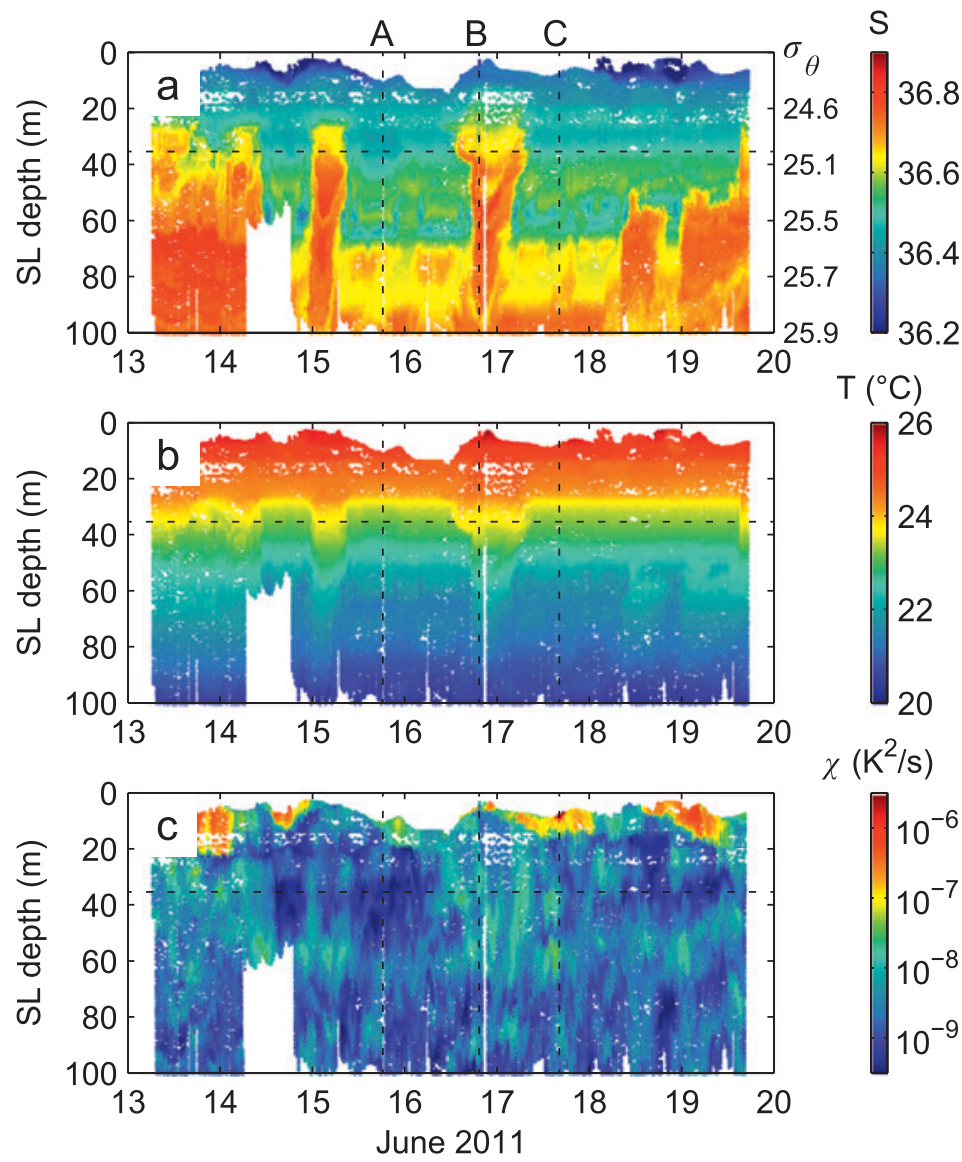

$\mathrm{S}$
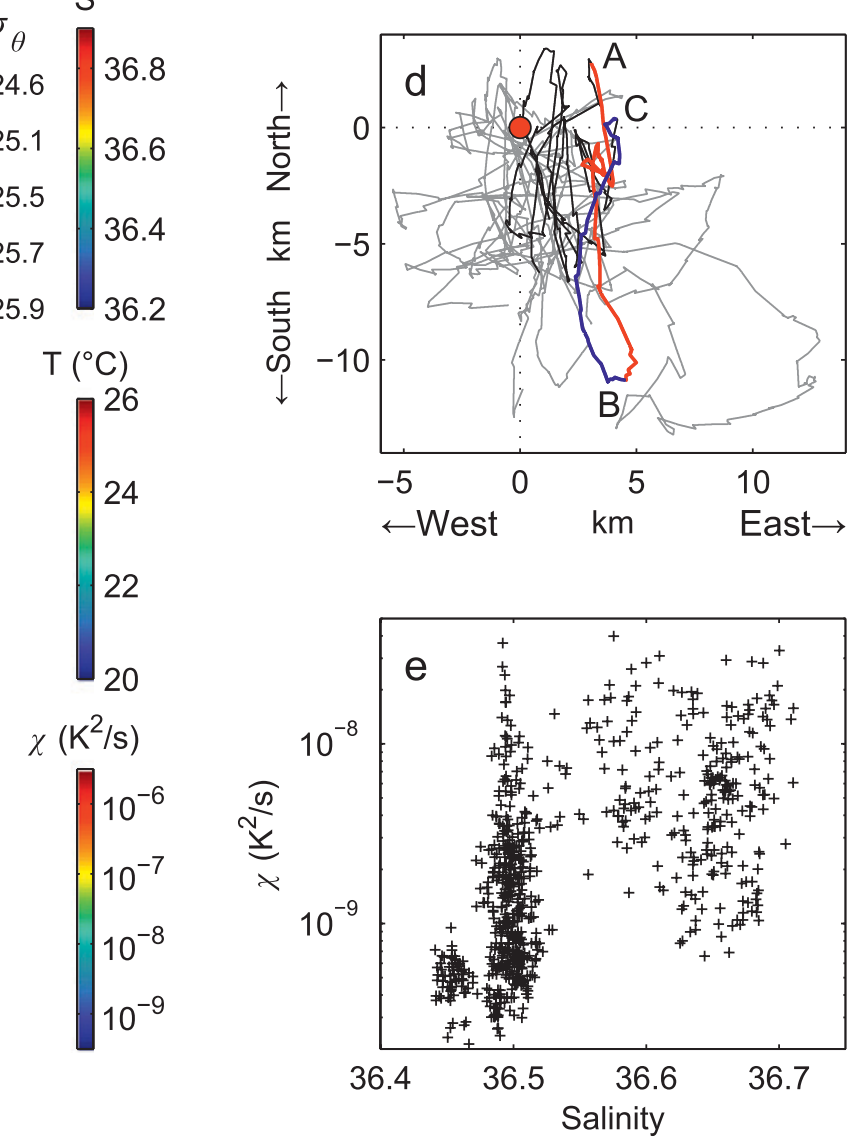

FIG. I6. Glider-based observations of (a) salinity, (b) temperature, and (c) dissipation of temperature variance during the moderate-straining case study (13-19 Jun 20II) as functions of time and isopycnal (semi-Lagrangian) depth; corresponding potential density values are marked on the right in (a). (d) All glider trajectories (gray) in the advected frame of reference moving with the center of mass of the drifter array (red circle). Trajectory of the single glider used to make the sections in (a)-(c) is shown in black. The glider turning points are marked with the vertical dashed lines and capital letters A-C; trajectory segments from point $A$ to B (red) and from $B$ to $C$ (blue) are highlighted in (d). (e) Dissipation of temperature variance at $\sigma_{\theta}=25.0 \mathrm{~kg} \mathrm{~m}^{-3}$ as a function of salinity; isopycnal level is marked with the horizontal dashed line in (a)-(c). Highest dissipation values occur in the warmer, saltier patches. 
anomalies around the 60-m isopycnal depth (25.5 isopycnal). This layer coincided with a layer of enhanced temperature variance dissipation as well.

Examination of the shear-dispersion hypothesis. The two rhodamine experiments provide an opportunity to evaluate the shear-dispersion hypothesis as the main mechanism responsible for the isopycnal diffusivity of $1 \mathrm{~m}^{2} \mathrm{~s}^{-1}$ inferred from the dye spreading (D. Birch et al. 2015, manuscript in preparation).

In both 6-day rhodamine experiments conducted during LatMix 2011, the dye patches elongated in the alongfront direction and compressed in the crossfront direction, as expected under the confluences. To evaluate the contributions of the vertical shear and lateral strain to the observed changes of the patch geometry, a simple semianalytical advectiondiffusion model was used. The evolution of the length, width, and tilts of the dye patches was simulated using velocities measured by shipboard ADCPs, a Lagrangian float, and the nine drifters. Velocity gradients in the model were assumed to be constant across the dye patch but were allowed to vary in time. Diapycnal diffusivities on the order of $5 \times 10^{-6} \mathrm{~m}^{2} \mathrm{~s}^{-1}$ inferred from the spreading of the dye in density space and from EM-APEX observations of dissipation (Fig. 15c) were imposed. Thus, shear dispersion arising from interaction of the resolved vertical shear (due to both internal waves and subinertial flows) and diapycnal mixing was explicitly included in the model. Explicit shear dispersion was not strong enough to account for the observed evolution of the dye patches in the context of this model. Isopycnal diffusivity due to the linearized shear field and diapycnal mixing was on the order of $0.1 \mathrm{~m}^{2} \mathrm{~s}^{-1}$. However, an isopycnal diffusivity an order of magnitude greater is required to explain the $\sim 1 \mathrm{~m}^{2} \mathrm{~s}^{-1}$ dispersion rate at scales of $1-5 \mathrm{~km}$ seen in the observations.

Unresolved shear is also unlikely to account for the observed isopycnal dispersion: traditional YRG82 internal-wave shear dispersion gives effective isopycnal diffusivity $K_{h} \sim\left\langle K_{v}\right\rangle\left\langle(\partial V / \partial z)^{2}\right\rangle f^{-2}=O(0.1) \mathrm{m}^{2} \mathrm{~s}^{-1}$ in both case studies, again assuming diapycnal diffusivities $\left\langle K_{v}\right\rangle=5 \times 10^{-6} \mathrm{~m}^{2} \mathrm{~s}^{-1}$ inferred from the observations. This is true whether $\left\langle(\partial V / \partial z)^{2}\right\rangle$ is based on ADCP observations or bounded by the Richardson number stability criterion of $\left\langle(\partial V / \partial z)^{2}\right\rangle \leq 4 N^{2}$, where $N$ is the buoyancy frequency. One possible explanation for the discrepancy is higher-order dynamics hitherto not accounted for in the traditional application of YRG82 shear-dispersion theory. Specifically, the YRG82 theory of internal-wave shear dispersion assumes uncorrelated Gaussian statistics for diapycnal diffusivity and shear. Since turbulence is produced by very intermittent internal-wave shear breaking, high shear and turbulence are both intermittent and correlated. A more appropriate expression for internal-wave shear dispersion then might be $\left\langle K_{v}(\partial X / \partial z)^{2}\right\rangle$, where $(\partial X / \partial z)=\int(\partial V / \partial z) d t$ is the vertical gradient of the horizontal displacement $X$ (Kunze and Sundermeyer 2014, manuscript submitted to J. Phys. Oceanogr.). Taking typical turbulence intermittency of $0.05-0.1$, for correlations of 0.5 or higher, effective isopycnal diffusivities of $O(1) \mathrm{m}^{2} \mathrm{~s}^{-1}$ are obtained, so that internal-wave shear dispersion cannot be ruled out. Proving that the latter dominates over other hypothesized mixing and stirring mechanisms remains an observational challenge.

Process modeling. Submesoscale-resolving simulations with $O(100) \mathrm{m}$ horizontal resolution and a two-equation algebraic closure model for subgrid turbulence were performed to examine submesoscale stirring (S. Mukherjee et al. 2015, manuscript in preparation). The simulation was initialized with a 20 -m-deep mixed layer front with lateral buoyancy gradient $3 \times 10^{-7} \mathrm{~s}^{-2}$ over $7 \mathrm{~km}$ and a baroclinic front with lateral gradient $1 \times 10^{-7} \mathrm{~s}^{-2}$ extending to $100 \mathrm{~m}$ to mimic the kilometer-scale gradients observed during the moderate-straining study on 13 June (Fig. 9a). Both an unforced spindown run and a run forced with the observed hourly wind stress were performed (see appendix for details).

The spindown simulation showed development of submesoscale subinertial instabilities of the thermohaline front and their evolution into streamers and filaments (Fig. 17). The simulation did not have any horizontal mesoscale confluence or mesoscale strain, which would likely stretch the features in the north-south direction. McWilliams et al. (2009) have theoretically shown that these instabilities persist when strain is imposed.

Lateral stirring associated with the instabilities produced salinity intrusions below the mixed layer, with characteristic scales of $O(2-5) \mathrm{km}$ in length and $O(10) \mathrm{m}$ in thickness. The simulated intrusions were somewhat larger than those observed during LatMix (Fig. 10) but had a similar aspect ratio. Resulting tracer dispersion corresponded to an effective lateral diffusivity of $1-5 \mathrm{~m}^{2} \mathrm{~s}^{-1}$ at $1-10-\mathrm{km}$ scale. Simulated isopycnal salinity gradient spectra below the mixed layer were flat (i.e., variance was independent of scale) for both spindown and wind-forced simulations in the resolved range $(0.5-10 \mathrm{~km})$, in agreement with the LatMix observations (Kunze et al. 2015). 

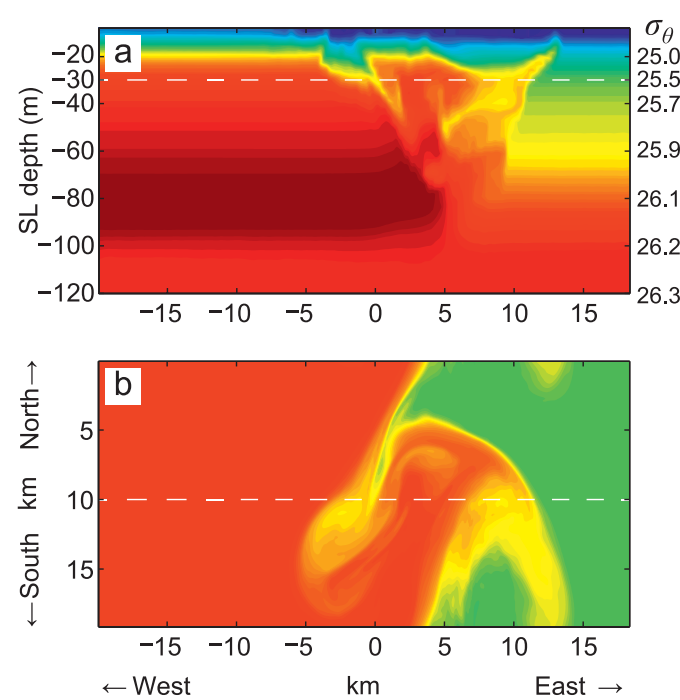

FIG. I7. Numerical submesoscale-resolving simulation of thermohaline front instability. (a) Zonal and (b) isopycnal sections of salinity 6.7 inertial periods after the initialization. The vertical axis in (a) is an isopycnal (semi-Lagrangian) depth; corresponding potential density values are shown on the right. Dashed lines mark the locations of isopycnal $\left(25.52 \mathrm{~kg} \mathrm{~m}^{-3}\right)$ and zonal $(10 \mathrm{~km})$ sections. The simulation was initialized with the observed thermohaline gradients (smoothed to I km) from the I 3 Jun hydrography (Fig. 9a) and allowed to evolve freely (spin down).

DISCUSSION AND SUMMARY. The 2011 LatMix field campaign accomplished several objectives on the way to its main goal of testing hypotheses for the mechanisms of lateral dispersion in the seasonal pycnocline at scales of $0.1-10 \mathrm{~km}$. The 6 -day duration of the rhodamine experiments ranks among the longest for fluorescent dye studies in the stratified ocean. Estimates of diapycnal and isopycnal diffusivity of the dye at the desired scales promise to be robust. Diapycnal diffusivity of the dye, averaged over several days and over tens of square kilometers of fluid $\left(<10^{-5} \mathrm{~m}^{2} \mathrm{~s}^{-1}\right)$, and the diffusivity of heat determined from profiles of temperature variance dissipation rate from the EM-APEX floats over the same time and space scales $\left(5 \times 10^{-6}\right.$ to $\left.10^{-5} \mathrm{~m}^{2} \mathrm{~s}^{-1}\right)$ appear to be consistent with one another. Measurements of dissipation rates of turbulent kinetic energy and temperature variance from the T-REMUS autonomous underwater vehicle deployed for approximately 8 -h periods are also consistent with the dye and EM-APEX measurements.

The campaign has shown the practicality of airborne lidar observations of dye patches during the first 6 hours of their evolution. The lidar effort is providing unique high-resolution, nearly synoptic surveys of the dye patches, from which ideas of the kinematics of dye dispersion at scales from 0.1 to $1 \mathrm{~km}$ may be formed. An unanticipated benefit of the lidar/dye work is a unique look at the evolution of a dye patch in the mixed layer, which provides evidence of stirring by a relatively recently recognized class of mixed layer instabilities (Sundermeyer et al. 2014).

The towed instruments, especially from the Moving Vessel Profiler on R/V Endeavor and Triaxus and Hammerhead on R/V Oceanus, give intriguing data on temperature-salinity (T/S) variability and its evolution in the vicinity of the weakly and moderately straining fronts on which the fieldwork was focused. For example, using salinity anomalies as a natural passive tracer, Kunze et al. (2015) reported a redder spectrum on the submesoscale than predicted by quasigeostrophic theory (Charney 1971; Scott 2006) as has previously been found (Ferrari and Rudnick 2000; Cole and Rudnick 2012; Callies and Ferrari 2013), implying additional straining submesoscale flows that might include contributions from nonquasigeostrophic subinertial flows and internal-wave processes.

A kinematic model based on the observed lateral strains, vertical shears, and diapycnal diffusivities suggests that traditional shear dispersion based on either resolved subinertial or unresolved internalwave shears cannot account for the $O(1) \mathrm{m}^{2} \mathrm{~s}^{-1}$ isopycnal dispersion exhibited by the dye patches at scales of 1-5 km. However, accounting for intermittency and log normality of turbulence and possible correlation between $K_{v}$ and shear $(\partial V / \partial z)$ suggests a possible way to restore the role of shear dispersion.

Numerical simulations have been performed in concert with the 2011 LatMix experiments by several groups in order to examine and test mechanisms of dispersion. Quasigeostrophic simulations have been run to isolate the role of stirring by mesoscale eddies in the LatMix region from additional stirring due to internal waves and submesoscale mixed layer instabilities. Submesoscale-resolving models have demonstrated stirring and mixing by frontal (S. Mukherjee et al. 2015, manuscript in preparation) and Kelvin-Helmholtz (Skyllingstad and Samelson 2012) instabilities. Large eddy simulations have reproduced the behavior of the mixed layer dye patch, pointing to the instability mechanism responsible for its behavior (Sundermeyer et al. 2014). Large eddy simulations have also been used to examine the behavior of a dye patch in an internal-wave field constructed to simulate that of the LatMix 2011 site with results that promise to sort out the effects of shear dispersion, adiabatic dispersion by internal waves alone, and vortical motions induced by diapycnal mixing events (M.-P. Lelong et al. 2015, manuscript in preparation). 
Among the original LatMix hypotheses, we considered four classes of motions that might dominate submesoscale stirring in the seasonal pycnocline: shear dispersion by internal waves; vortices induced by diapycnal mixing events; a downward cascade of stirring motions from the mesoscale; and submesoscale instabilities. We are not yet in a position to rule out any of them, and in fact a reasonable hypothesis at the moment seems to be that they all contribute. In the 2011 LatMix campaign, however, we have gathered data that are enabling us to better describe and quantify each class of motion. Already, in the analysis and synthesis of the observations and the models, new ideas as well as new questions have arisen. The program has brought together investigators with many perspectives, insuring that synthesis will continue to be lively and critically thorough.

ACKNOWLEDGMENTS. We thank Office of Naval Research, particularly Terri Paluszkiewicz and Scott Harper, for support of the LatMix. The bulk of this work was funded under the Scalable Lateral Mixing and Coherent Turbulence Departmental Research Initiative and the Physical Oceanography Program. The dye experiments were supported jointly by the Office of Naval Research and the National Science Foundation Physical Oceanography Program (Grants OCE-0751653 and OCE-0751734).

We are grateful to the captains and crews of R/Vs Cape Hatteras, Endeavor, and Oceanus, as well as the Navy Lockheed P3 Orion aircraft who made these observations possible. Many thanks to the LatMix team of ocean engineers and support staff: Mike Ohmart and Mike Kenney (Lagrangian float); John Dunlap, Jim Carlson, and Avery Snyder (EM-APEX); Chris MacKay and Kevin Bartlett (Hammerhead); Jason Gobat, Ben Jokinen, and Dave Winkel (Triaxus); Brian Guest and Leah Houghton (dye); Deborah Debiegun (drogued drifters); Cynthia Sellers and Laura Stolp (shipboard data); and many others. We thank Jules Hummon and Eric Firing for their help in calibration and processing shipboard ADCP. We also appreciate the efforts of three anonymous reviewers and their comments.

In memoriam of Murray Levine.

\section{APPENDIX: INSTRUMENT/PLATFORM} DESCRIPTION. Shipboard instruments. ADCP: Each of the three research vessels was equipped with a pair of Teledyne RD Instruments acoustic Doppler current profilers (ADCPs): $150-$ and $600-\mathrm{kHz}$ Workhorse ADCPs on R/V Cape Hatteras and $300-\mathrm{kHz}$ Workhorse and 75-kHz Ocean Surveyor on R/Vs Endeavor and Oceanus. Vertical resolution varied from 2 to $8 \mathrm{~m}$. All ADCP data were collected and processed using the University of Hawaii Data
Acquisition System (UHDAS) data acquisition, processing, distribution, and monitoring system (Firing and Hummon 2010).

UCTD: Each vessel was also equipped with an underway thermosalinograph (UCTD) to continuously monitor near-surface temperature and salinity from a flow-through system.

Towed instruments. Dye injection: The density of the rhodamine water tracing (WT) and fluorescein dye mixtures was adjusted to within $1 \mathrm{~kg} \mathrm{~m}^{-3}$ of the density of the target seawater by diluting with isopropyl alcohol in 200-L drums. The dye mixture was injected by pumping from the drums through a garden hose coupled to the CTD cable with cable ties. At the end of the CTD cable hung a depressor weight about $1 \mathrm{~m}$ below the termination, and streaming about $2 \mathrm{~m}$ behind the termination was a neutrally buoyant package comprising a frame, flotation, a Seabird-9 CTD, and a T-shaped diffuser at the end of the garden hose. The package was kept within less than $1 \mathrm{~m} \mathrm{rms}$ of the target density surface by manually controlling the CTD winch in response to the density deviation measured by the CTD. The system was towed from the waist of the ship, to minimize the effect of ship motion, at a speed of about $1 \mathrm{knot}\left(\mathrm{kt} ; 1 \mathrm{kt}=0.51 \mathrm{~m} \mathrm{~s}^{-1}\right)$ for approximately $1 \mathrm{~h}$ for the rhodamine releases and $15 \mathrm{~min}$ for the fluorescein releases. The ship's heading was determined by the wind and sea state to minimize ship motion and keep the wire away from the hull. Towing while injecting had the disadvantage of creating turbulent wake, which spread the dye in density space. However, the turbulence also had the positive effect of diminishing the density anomaly of the dye mixture by dilution. Releasing the dye in a streak rather than a spot also had the advantages of making the dye easier to sample early in the experiments and of allowing the dye to sample a variety of mixing conditions from the very beginning.

Triaxus is a towed, undulating vehicle designed for making quasi-synoptic, high-resolution, threedimensional surveys of the upper ocean. During the LatMix 2011 experiment, Triaxus was typically towed at 7-8 kt while undulating between the surface and $100 \mathrm{~m}$, producing along-track horizontal resolution of about $1 \mathrm{~km}$. The sensor suite included a Seabird CTD, upward- and downward-looking ADCPs, dye fluorometer, transmissometer, and dissolved oxygen sensor, with a fiber-optic tow cable providing telemetry.

Moving Vessel Profiler (MVP), manufactured by ODIM Brooke Ocean/Rolls-Royce, employs an instrumented free-fall fish to measure vertical 
profiles of pressure, temperature, conductivity, and rhodamine dye fluorescence down to 50-200-m depth while underway at 6-8 kt. During the LatMix 2011 experiment, typical horizontal spacing of $100-\mathrm{m}$ depth profiles was $0.55 \mathrm{~km}$ at $7 \mathrm{kt}$. Two MVPs were used during the LatMix 2011 experiment: UVic MVP on R/V Endeavor and the OSU MVP on R/V Cape Hatteras.

The Acrobat (manufactured by Sea Sciences, Inc.) is a winged towed body that uses its control surfaces to modulate its depth. For the LatMix program, it was equipped with an RBR CTD and three Turner Cyclops fluorometers, one each to sense rhodamine, fluorescein, and chlorophyll-a. The majority of the rhodamine dye surveys and three of the six fluorescein dye surveys conducted during LatMix 2011 were conducted with the Acrobat. Vertical resolutions of the surveys were typically on the order of $10 \mathrm{~cm}$ within the dye patches, whereas horizontal resolutions were on the order of $150 \mathrm{~m}$.

Hammerhead is a Rockland Scientific towyo body equipped with pumped Seabird temperature and conductivity sensors; a pressure sensor; an electromagnetic (EM) velocity sensor to measure motion through the water; and Chelsea fluorescein, rhodamine, and chlorophyll optical sensors. LatMix 2011 was its first open-ocean use and it was deployed eight times. It conducted 2-km-radius circles around the Gateway buoy for 5-9-h intervals, while T-REMUS was conducting $1-\mathrm{km}$ box surveys. It was towyoed in a 10 -m vertical aperture about the target density of the rhodamine and fluorescein dye injections.

Autonomous platforms. Four Slocum Electric gliders (Teledyne Webb Research) were deployed to fly a coherent survey pattern relative to the moving drifter that marked the approximate location of the rhodamine dye patch. The coherent survey pattern for the gliders was a 12-km-long tic-tac-toe with two gliders running parallel lines separated by $4 \mathrm{~km}$ (e.g., north to south) and the other two gliders running perpendicular lines (e.g., east to west). Two gliders (350-m Webb Slocum) were equipped with 1-Hz CTD (SBE 41); single-wavelength backscatter, chlorophyll, and rhodamine fluorescence (WETLabs FLBBRH); fluorescein fluorescence (FLUR); and $600-\mathrm{kHz}$ phased array DVL (RDI): gliders John (unit 185) and June (unit 186). Two gliders (200-m Webb Slocum) were equipped with CTD (SBE 41) and homemade microstructure packages with two thermistors, two shear probes, and a six-port pressure sensor "gust probe": gliders Doug (unit 93) and Russ (unit 91). The gliders undulated from about 2-m to 200- or 350-m depth at a vertical rate of $15 \mathrm{~cm} \mathrm{~s}^{-1}$. The horizontal speed of the gliders was $25 \mathrm{~cm} \mathrm{~s}^{-1}$. Vertical resolution was less than $1 \mathrm{~m}$ and along-track resolution was less than $1 \mathrm{~km}$. The $600-\mathrm{kHz}$ ADCPs on John and June were set to 4 -m vertical bins and 10 -s ensembles sampling at about $1 \mathrm{~Hz}$. Absolute velocity profiles were computed from all the velocity measurements between glider surfacings (Ordonez et al. 2012).

Seaglider: A fifth glider (1000-m UW Seaglider) was equipped with $0.5-\mathrm{Hz}$ CTD (SBE 41), dissolved oxygen (SBE 43), single wavelength backscatter, chlorophyll and colored dissolved organic matter fluorescence (WETLabs FLNTU), and photosynthetic active radiation (Satlantic) sensor: glider sg158. The Seaglider undulated from the surface to 1000 -m depth at a vertical rate of about $20 \mathrm{~cm} \mathrm{~s}^{-1}$. The CTD was sampled at 4-120-s intervals depending on depth range (higher resolution near the surface). A full dive took approximately $6 \mathrm{~h}$. Horizontal speed was $20 \mathrm{~cm} \mathrm{~s}^{-1}$, leading to a horizontal resolution of about $5 \mathrm{~km}$.

T-REMUS is a custom-designed REMUS 100 autonomous underwater vehicle (AUV) manufactured by Hydroid Inc. It is 2-m long, 19-cm diameter, and $63 \mathrm{~kg}$ in mass. It has a depth range of $100 \mathrm{~m}$ and can be deployed for up to $20 \mathrm{~h}$. During the LatMix 2011 experiment, T-REMUS was operated on seven separate runs typically on the order of $8 \mathrm{~h}$ in a yoyo mode spanning the depth range of 25 to $45 \mathrm{~m}$ using a $10^{\circ}$ descent/ascent angle. A Lagrangian three-buoy drogued system (Gateway buoy) was developed to provide navigation and communication with T-REMUS. This configuration allowed the AUVbased measurements to be both along and across prescribed isopycnals and to be taken in an approximate Lagrangian coordinate system with respect to the mean flow at the center depth of the drogue. Sensors on the T-REMUS include the Rockland Scientific MicroRider microstructure measurement system, upward- and downward-looking 1.2-MHz RDI ADCPs, a Seabird SBE 49 "FastCAT" CTD, and a WetLabs ECO Puck Triplet, combining a spectral backscattering meter and a chlorophyll fluorometer.

Drifters and floats. The EM-APEX is a Teledyne Webb Research Inc. APEX float with dual, orthogonal electrode arms, which sense the motionally induced electric currents in the ocean (Sanford et al. 2005). In addition to measuring the velocity profile derived from the electric field measurements, relative to a depth-uniform offset, the float measured temperature, salinity, and pressure with a SeaBird 41 CTD. A total of 21 floats were available, and 10 floats also carried a pair of FP-07 fast-response 
thermistors and a SeaBird 41CP CTD to observe $\chi$, a measure of thermal variance dissipation rate. The floats were programmed to profile continuously and synchronously from the surface to $150 \mathrm{~m}$, a cycle that required about $50 \mathrm{~min}$. Profiles of pressure, temperature, salinity, velocity, and surface GPS positions were transferred via iridium before the swarm began the next synchronized dive. Depth-uniform velocity offsets were corrected by considering the integral drift of the floats over the duration of each dive estimated from surface GPS fixes. Uncertainty of the resulting absolute velocities was $1-2 \mathrm{~cm} \mathrm{~s}^{-1}$ based on the RMS velocity differences of nearby simultaneous profiles. Three swarm deployments were made, with a few floats also recovered and redeployed for repair or to improve spatial coverage. The float data were received and archived at APL-UW and retransmitted to R/V Endeavor via HiSeasNet. The raw microthermistor measurements were retrieved only on instrument recovery after each deployment.

The drogued drifters released with the dye by the University of Massachusetts Dartmouth team consisted of a 40-cm-diameter surface float with a polyvinyl chloride (PVC) spar holding a strobe and a satellitetracked ComTech GPS device. The surface float was tethered via a 3-mm-diameter Maxibraid tether to a 6.3-m-long, 1-m-diameter holey sock drogue, typically centered at the target dye injection depth. For drogue depths and tether lengths used in the present study, a drag ratio of $\sim 40: 1$ was maintained between the drogue and tether plus surface expression of the drifter. Drifters were tracked in real time, with position fixes at 0.5 -h intervals relayed to the ship and an estimated horizontal accuracy ranging from 10 to $100 \mathrm{~m}$.

SVP drifters: 20 standard Surface Velocity Program (SVP) drifters were deployed during LatMix 2011 in collaboration with the Global Drifter Program administered by the National Oceanic and Atmospheric Administration (NOAA) Atlantic Oceanographic and Meteorological Laboratory. Each SVP drifter consisted of a satellite-tracked surface buoy and a subsurface drogue centered at a depth of $15 \mathrm{~m}$. Drifter sensors measured sea surface temperature, which was averaged over a 90-s window and telemetered to shore via Argos satellite network. Positions of SVP drifters were determined from Argos signal Doppler shifts, with an estimated accuracy of 250-1500 m. Relatively high positional uncertainty make SVP drifters of limited use for dispersion studies (Haza et al. 2014).

Lagrangian floats (D'Asaro 2003) are metersized subsurface neutrally buoyant autonomous instruments, designed to accurately follow the three-dimensional motion of water parcels through a combination of neutral buoyancy and high drag provided by a folding horizontal drogue. For the LatMix experiment, one of the floats was outfitted with a rotating chain-drive mechanism, transporting a SeaBird SBE-39 temperature sensor and a Wetlabs ECO-FLURB fluorometer across the 1.2-m height of the float every $30 \mathrm{~s}$ (Fig. 14a).

Remote sensing and models. The lidar system, tuned for fluorescein, was flown in a Navy P3 Orion aircraft. Complete surveys of the patch took an hour or so, and the aircraft was over the site for as many as $6 \mathrm{~h}$ so that multiple surveys could be acquired. Nominal resolution of the surveys was approximately $10 \mathrm{~m}$ in the horizontal by $1 \mathrm{~m}$ in the vertical; the surface swath of the conically swept lidar beam was about $200 \mathrm{~m}$.

High-resolution SST imagery was obtained from Advanced Very High Resolution Radiometers (AVHRR) on board NOAA-15, NOAA-18, NOAA-19, and Meteorological Operational-2 (MetOp-2) satellites. Gridded L3 data were obtained from NOAA CoastWatch data center (http://coastwatch.noaa .gov/). Additional high-resolution SST data, plus maps of diffuse attenuation coefficient (K490; proxy for water clarity) were obtained by the National Aeronautics and Space Administration (NASA) Moderate Resolution Imaging Spectroradiometers (MODIS) on board the Aqua and Terra satellites and processed by the NASA Jet Propulsion Laboratory Ocean Biology Processing Group and the University of Miami, Miami, Florida. Lowerresolution SST maps from the Tropical Rainfall Measuring Mission (TRMM) Microwave Imager (TMI) and the Advanced Microwave Scanning Radiometer for Earth Observing System (AMSR-E) were obtained from Remote Sensing Systems. Nearreal-time access of MODIS, TMI, and AMSR-E data were facilitated by the Group for High Resolution SST Master Metadata Repository.

Satellite altimetry products, including along-track and merged absolute dynamic topography maps, were produced by Segment Sol Multimissions d'Altimétrie, d'Orbitographie et de Localisation Précise (SSALTO)/ Developing Use of Altimetry for Climate Studies (DUACS) and distributed in near-real time by Archiving, Validation and Interpretation of Satellite Oceanographic Data (AVISO), with support from the Centre Nationale d'Etudes Spatiales, France (www aviso.oceanobs.com/duacs/).

Operational models: Regional-scale predictions from the Hybrid Coordinate Model and the Global Navy Coastal Ocean Model were produced by the Naval Oceanographic Office using the Navy Coupled 
Ocean Data Assimilation system and obtained via distribution by the Hybrid Coordinate Ocean Model (HYCOM) Consortium and by the Naval Oceanographic Office (NAVOCEANO), respectively.

Process model: The Process Study Ocean Model (PSOM) is a three-dimensional, nonhydrostatic, free-surface model (Mahadevan 2006), where the top layer of grid cells moves with the surface. The grid is stretched in the vertical for finer resolution near the free surface. The model is periodic in the meridional direction with zero fluxes of momentum and scalar quantities across the zonal boundaries. Vertical subgrid diffusivities are parameterized with $k-\varepsilon$ turbulence closure; the lateral diffusivities are set to zero. The LatMix simulations (Fig. 17) were performed with $0.1-\mathrm{km}$ lateral resolution, with the vertical resolution varying from $O(1) \mathrm{m}$ near the surface to $O(10) \mathrm{m}$ near the bottom at $200 \mathrm{~m}$. The model time step was $108 \mathrm{~s}$. Hourly averaged wind stress computed from R/V Endeavor observations using the Tropical Ocean and Global Atmosphere Coupled Ocean-Atmosphere Response Experiment (TOGA COARE) algorithm for 13-21 June was used in wind-forced runs.

\section{REFERENCES}

Badin, G., A. Tandon, and A. Mahadevan, 2011: Lateral mixing in the pycnocline by baroclinic mixed layer eddies. J. Phys. Oceanogr., 41, 2080-2101, doi:10.1175 /JPO-D-11-05.1.

Boccaletti, G., R. Ferrari, and B. Fox-Kemper, 2007: Mixed layer instabilities and restratification. J. Phys. Oceanogr., 37, 2228-2250, doi:10.1175/JPO3101.1.

Brunner-Suzuki, A.-E. G., M. A. Sundermeyer, and M.-P. Lelong, 2014: Upscale energy transfer induced by vortical modes and internal waves. J. Phys. Oceanogr., 44, 2446-2469, doi:10.1175/JPO-D-12-0149.1.

Bühler, O., N. Grisouard, and M. Holmes-Cerfon, 2013: Strong particle dispersion by weakly dissipative random internal waves. J. Fluid Mech., 719, R4, doi:10.1017/jfm.2013.71.

Callies, J., and R. Ferrari, 2013: Interpreting energy and tracer spectra of upper-ocean turbulence in the submesoscale range (1-200 km). J. Phys. Oceanogr., 43, 2456-2474, doi:10.1175/JPO-D-13-063.1.

Capet, X., J. C. McWilliams, M. J. Molemaker, and A. F. Shchepetkin, 2008: Mesoscale to submesoscale transition in the California Current system. Part I: Flow structure, eddy flux, and observational tests. J. Phys. Oceanogr., 38, 29-43, doi:10.1175/2007JPO3671.1.

Charney, J. G., 1971: Geostrophic turbulence. J. Atmos. Sci., 28, 1087-1095, doi:10.1175/1520 -0469(1971)028<1087:GT>2.0.CO;2.
Cole, S. T., and D. L. Rudnick, 2012: The spatial distribution and annual cycle of upper ocean thermohaline structure. J. Geophys. Res., 117, C02027, doi:10.1029/2011JC007033.

D'Asaro, E. A., 2003: Performance of autonomous Lagrangian floats. J. Atmos. Oceanic Technol., 20, 896-911, doi:10.1175/1520-0426(2003)020<0896: POALF $>2.0 . \mathrm{CO} ; 2$.

Eckart, C., 1948: An analysis of the stirring and mixing processes in incompressible fluids. J. Mar. Res., 7, 265-275.

Ferrari, R., and D. L. Rudnick, 2000: Thermohaline variability in the upper ocean. J. Geophys. Res., 105, 16857-16883, doi:10.1029/2000JC900057.

Firing, E., and J. M. Hummon, 2010: Ship-mounted acoustic Doppler current profilers. The GO-SHIP repeat hydrography manual: A collection of expert reports and guidelines, IOCCP Rep. 14 ICPO Publ. 134, 11 pp. [Available online at www.go-ship .org/Manual/Firing_SADCP.pdf.]

Garrett, C., 2006: Turbulent dispersion in the ocean. Prog. Oceanogr., 70, 113-125, doi:10.1016/j .pocean.2005.07.005.

- , and W. Munk, 1979: Internal waves in the ocean. Annu. Rev. Fluid Mech., 11, 339-369, doi:10.1146 /annurev.fl.11.010179.002011.

Gregg, M. C., 1987: Diapycnal mixing in the thermocline: A review. J. Geophys. Res., 92, 5249-5289, doi:10.1029/JC092iC05p05249.

— 1989: Scaling turbulent dissipation in the thermocline. J. Geophys. Res., 94, 9686-9698, doi:10.1029 /JC094iC07p09686.

Haza, A. C., T. M. Özgökmen, A. Griffa, A. C. Poje, and P. Lelong, 2014: How does drifter position uncertainty affect ocean dispersion estimates? J. Atmos. Oceanic Technol., 31, 2809-2828, doi:10.1175 /JTECH-D-14-00107.1.

Kunze, E., J. M. Klymak, R.-C. Lien, R. Ferrari, C. M. Lee, M. A. Sundermeyer, and L. Goodman, 2015: Submesoscale water-mass spectra in the Sargasso Sea. J. Phys. Oceanogr., 45, 1325-1338, doi:10.1175 /JPO-D-14-0108.1.

Ledwell, J. R., A. J. Watson, and C. S. Law, 1998: Mixing of a tracer in the pycnocline. J. Geophys. Res., 103, 21 499-21 529, doi:10.1029/98JC01738.

Lien, R.-C., and P. Müller, 1992: Normal-mode decomposition of small-scale oceanic motions. $J$. Phys. Oceanogr., 22, 1583-1595, doi:10.1175/1520 -0485(1992)022<1583:NMDOSS>2.0.CO;2.

MacKinnon, J., L. S. Laurent, and A. Naviera Garabato, 2013: Diapycnal mixing processes in the ocean interior. Ocean Circulation and Climate: A 21st Century Perspective, G. Siedler et al., Eds., Academic Press, 159-184. 
Mahadevan, A., 2006: Modeling vertical motion at ocean fronts: Are nonhydrostatic effects relevant at submesoscales? Ocean Modell., 14, 222-240, doi:10.1016/j.ocemod.2006.05.005.

— nisms for submesoscale vertical motion at ocean fronts. Ocean Modell., 14, 241-256, doi:10.1016 /j.ocemod.2006.05.006.

McDougall, T. J., 1984: The relative roles of diapycnal and isopycnal mixing on subsurface water mass conversion. J. Phys. Oceanogr., 14, 1577-1589, doi:10.1175/1520-0485(1984)014<1577:TRRODA $>2.0 . \mathrm{CO} ; 2$.

McWilliams, J. C., M. J. Molemaker, and I. Yavneh, 2001: From stirring to mixing of momentum: Cascades from balanced flows to dissipation in the oceanic interior. From Stirring to Mixing in a Stratified Ocean: Proc. 12th 'Aha Huliko'a Hawaiian Winter Workshop, Honolulu, HI, University of Hawai' i at Mānoa, 59-66.

,-- , and E. I. Olafsdottir, 2009: Linear fluctuation growth during frontogenesis. J. Phys. Oceanogr., 39, 3111-3129, doi:10.1175/2009JPO4186.1.

Molemaker, J. J., J. C. McWilliams, and X. Capet, 2010: Balanced and unbalanced routes to dissipation in an equilibrated Eady flow. J. Fluid Mech., 654, 35-63, doi:10.1017/S0022112009993272.

Montgomery, R. B., 1940: The present evidence on the importance of lateral mixing processes in the ocean. Bull. Amer. Meteor. Soc., 21, 87-94.

Moum, J. N., and J. D. Nash, 2009: Mixing measurements on an equatorial ocean mooring. J. Atmos. Oceanic Technol., 26, 317-336, doi:10.1175/2008JTECHO617.1.

Müller, P., J. McWilliams, and J. Molemaker, 2005: Routes to dissipation in the ocean: The $2 \mathrm{D} / 3 \mathrm{D}$ turbulence conundrum. Marine Turbulence, H. Z. Baumert, J. Simpson, and J. Sündermann, Eds., Cambridge University Press, 397-405.

Okubo, A., 1976: Remarks on the use of 'diffusion diagrams' in modeling scale-dependent diffusion. Deep-Sea Res. Oceanogr. Abstr., 23, 1213-1214, doi:10.1016/0011-7471(76)90897-4.

Ordonez, C. E., R. K. Shearman, J. A. Barth, P. Welch, A. Erofeev, and Z. Kurokawa, 2012: Obtaining absolute water velocity profiles from glider-mounted acoustic Doppler current profilers. Proc. OCEANS 2012, Yeosu, South Korea, IEEE, doi:10.1109 /OCEANS-Yeosu.2012.6263582.

Ozmidov, R. V., 1958: On the calculation of horizontal turbulent diffusion of the pollutant patches in the sea. Dokl. Akad. Nauk SSSR, 120, 761-763.

Pinkel, R., 2014: Vortical and internal-wave shear and strain. J. Phys. Oceanogr., 44, 2070-2092, doi:10.1175 /JPO-D-13-090.1.
Polzin, K. L., J. M. Toole, and R. W. Schmitt, 1995: Finescale parameterizations of turbulent dissipation. J. Phys. Oceanogr., 25, 306-328, doi:10.1175 /1520-0485(1995)025<0306:FPOTD>2.0.CO;2.

Sanford, T. B., J. H. Dunlap, J. A. Carlson, D. C. Webb, and J. B. Girton, 2005: Autonomous velocity and density profiler: EM-APEX. Proc. Eighth Working Conf. on Current Measurement Technology, Southampton, United Kingdom, IEEE/OES, 152-154.

Scott, R. K., 2006: Local and nonlocal advection of a passive tracer. Phys. Fluids, 18, 116601, doi:10.1063 /1.2375020.

Shcherbina, A. Y., M. C. Gregg, M. H. Alford, and R. R. Harcourt, 2010: Three-dimensional structure and temporal evolution of submesoscale thermohaline intrusions in the North Pacific subtropical frontal zone. J. Phys. Oceanogr., 40, 1669-1689, doi:10.1175/2010JPO4373.1.

Skyllingstad, E. D., and R. M. Samelson, 2012: Baroclinic frontal instabilities and turbulent mixing in the surface boundary layer. Part I: Unforced simulations. J. Phys. Oceanogr., 42, 1701-1716, doi:10.1175 /JPO-D-10-05016.1.

Smith, K. S., and R. Ferrari, 2009: The production and dissipation of compensated thermohaline variance by mesoscale stirring. J. Phys. Oceanogr., 39, 2477-2501, doi:10.1175/2009JPO4103.1.

Stern, M. E., 1975: Ocean Circulation Physics. Academic Press, 246 pp.

Stommel, H., 1949: Horizontal diffusion due to oceanic turbulence. J. Mar. Res., 8, 199-225.

Sundermeyer, M. A., and J. R. Ledwell, 2001: Lateral dispersion over the continental shelf: Analysis of dye release experiments. J. Geophys. Res., 106, 9603, doi:10.1029/2000JC900138.

,-- , N. S. Oakey, and B. J. W. Greenan, 2005: Stirring by small-scale vortices caused by patchy mixing. J. Phys. Oceanogr., 35, 1245-1262, doi:10.1175 /JPO2713.1.

— E. Skyllingstad, J. R. Ledwell, B. Concannon, E. A. Terray, D. Birch, S. Pierce, and B. Cervantes, 2014: Observations and numerical simulations of large eddy circulation in the ocean surface mixed layer. Geophys. Res. Lett., 41, 7584-7590, doi:10.1002/2014GL061637.

Thomas, L. N., A. Tandon, and A. Mahadevan, 2008: Submesoscale processes and dynamics. Ocean Modeling in an Eddying Regime, Geophys. Monogr., Vol. 177, Amer. Geophys. Union, 17-38.

Young, W. R., P. B. Rhines, and C. J. R. Garrett, 1982: Shear-flow dispersion, internal waves and horizontal mixing in the ocean. J. Phys. Oceanogr., 12, 515-527, doi:10.1175/1520-0485(1982)012<0515: SFDIWA $>2.0 . \mathrm{CO} ; 2$. 


\section{$\mathrm{S}$
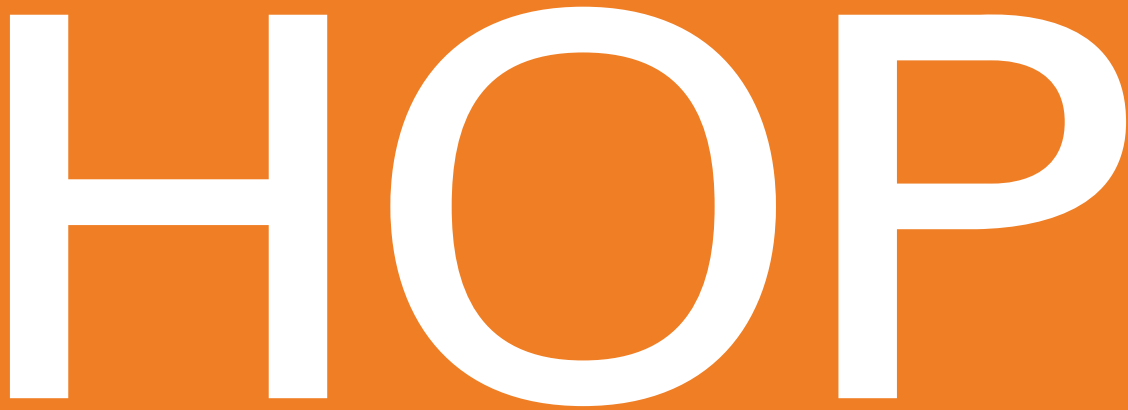 \\ the new AMS online bookstore}

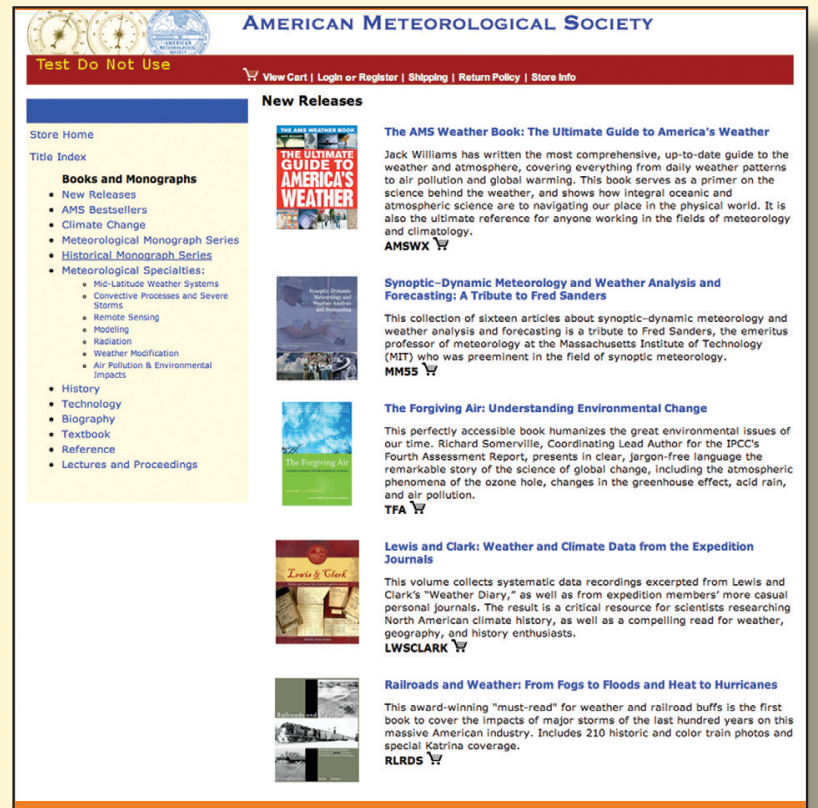

Use this easy-to-navigate site to review and purchase new and classic titles in the collection of AMS Books-including general interest weather books, histories, biographies, and monographsplus much more.

View tables of contents, information about the authors, and independent reviews.

As always, AMS members receive deep discounts on all AMS Books.

\section{www.ametsoc.org/amsbookstore The new AMS online bookstore is now open.}

Booksellers and wholesale distributors may set up accounts with our distributor, The University of Chicago Press, by contacting Karen Hyzy at khyzy@press.uchicago.edu, 773-702-7000, or toll-free at 800-621-2736. 